\title{
Pressurized OCC Process Ideally Flexible to the Thermal Load
}

\author{
Hussam Zebian $^{\mathrm{a}}$, Alexander Mitsos ${ }^{\mathrm{a}, \mathrm{b}, 1}$ \\ ${ }^{a}$ Department of Mechanical Engineering \\ Massachusetts Institute of Technology \\ 77 Massachusetts Avenue \\ Cambridge, MA 02139, USA \\ ${ }^{b}$ AVT Process Systems Engineering (SVT), RWTH Aachen University, \\ Turmstrasse 46, Aachen, 52064, Germany
}

\begin{abstract}
A pressurized oxycoal combustion process is optimized for variable thermal loading (100\% to $30 \%$ ). The steam expansion line behavior is accurately represented based on manufacturer data. Simulations with the nominal design and nominal operation are then performed with variable loads to determine the level of performance decrease if no optimization is performed. Finally, optimization of operation for a fixed design, and simultaneous optimization of design and operation are performed. The design optimization for a specific load does not include the redesign of the turbines to a process specifically designed for this load. However, the design variables of the turbine expansion line, namely the extraction bleeds, are considered. At each load, the performance of the process designed for nominal load is compared to the maximum possible performance obtained when designing the process for that specific load. Thanks to the thermal recovery section, the process exhibits ideal flexibility to load variations (not accounting for efficiency variations in the air separation unit, hence assuming oxygen storage), unlike Rankine cycles without pressurized recovery. Consequently, there is no need to optimize for an expected distribution of load operations. Finally, the process maintains supercritical working-fluid conditions over larger ranges of thermal loads.
\end{abstract}

Keywords: Variable load optimization, Pressurized Oxy-Coal, Load flexibility, Flue gas recovery

\section{Nomenclature}

\begin{tabular}{ll|ll} 
ASU & Air Separation Unit & CCS & Carbon Capture and Sequestration \\
Cool-Gas & Flue Gas at exit of HRSG & FG-Rec-pri & Primary Recycled Flue Gas \\
FG-Rec-sec & Secondary Recycled Flue Gas & FG-RHE-in & Flue Gas entering the RHE \\
FWH & Feedwater Heater & FW-HRSG-in & Feedwater entering HRSG \\
FW-RHE-in & Feedwater RHE in/Feedwater en- & HHV & Higher Heating Value of Coal \\
& tering RHE & & (MJ/kg) \\
Hot-Gas & Flue gas entering the HRSG & HP-Pump & High-Pressure Pump
\end{tabular}

\footnotetext{
${ }^{1}$ corresponding author: amitsos@alum.mit.edu
}

Preprint submitted to Energy 


\begin{tabular}{ll|ll}
\hline HRSG & Heat Recovery Steam Generator & LHV & $\begin{array}{l}\text { Lower Heating Value of Coal } \\
(\mathrm{MJ} / \mathrm{kg})\end{array}$ \\
LP-Pump & Low-Pressure Pump & \\
OCC & Oxy-Coal Combustion & RHE & $\begin{array}{l}\text { Recovery Heat Exchanger. Acid } \\
\text { condensation occurs in RHE }\end{array}$
\end{tabular}

\section{Optimization Variables and Constraints}

\begin{tabular}{|c|c|}
\hline BLD1_stage & Bleed1 extraction stage \\
\hline BLD3_stage & Bleed 3 extraction stage \\
\hline CO2_pure & Purity of $\mathrm{CO}_{2}$ captured \\
\hline$\dot{m}_{\mathrm{FW}, \text { main }}$ & Main feedwater flowrate $(\mathrm{kg} / \mathrm{s})$ \\
\hline MITA_FWH1 & FWH1 pinch $\left({ }^{\circ} \mathrm{C}\right)$ \\
\hline MITA_HRSG & HRSG pinch $\left({ }^{\circ} \mathrm{C}\right)$ \\
\hline $\mathrm{P}_{\text {BLD\# }}$ & Bleed\# extraction pressure (bar) \\
\hline $\mathrm{P}_{\text {Deaerator }}$ & Deaerator pressure (bar) \\
\hline$\dot{Q}_{\mathrm{Comb}}$ & Combustor Duty (MW) \\
\hline$\dot{Q}_{\mathrm{FWH} \#}$ & Feedwater Heater \# duty (kW) \\
\hline $\mathrm{T}_{\text {Cool-Gas }}$ & Temperature of flue gas exiting the \\
\hline & $\operatorname{HRSG}\left({ }^{\circ} \mathrm{C}\right)$ \\
\hline $\mathrm{T}_{\mathrm{FW}-H R S G-i n}$ & $\begin{array}{l}\text { Temperature of feedwater entering } \\
\text { the HRSG }\left({ }^{\circ} \mathrm{C}\right)\end{array}$ \\
\hline
\end{tabular}
BLD2_stage Bleed2 extraction stage
CO2_Cap Ratio of $\mathrm{CO}_{2}$ capture to total pro- duced
$\dot{m}_{\text {BLD\# }} \quad$ Bleed\# flowrate $(\mathrm{kg} / \mathrm{s})$
MITA Minimum internal temperature ap- proach $\left({ }^{\circ} \mathrm{C}\right)$
MITA_FWH2 FWH2 pinch $\left({ }^{\circ} \mathrm{C}\right)$
MITA_RHE RHE pinch $\left({ }^{\circ} \mathrm{C}\right)$
$\mathrm{P}_{\mathrm{Comb}} \quad$ Combustion Pressure (bar)
qDeaerator Quality in Deaerator tank
$\mathrm{T}_{\text {FG-RHE-out }} \quad$ Flue gas temperature at RHE exit $\left({ }^{\circ} \mathrm{C}\right)$

$\mathrm{T}_{\text {Comb-Gas-in }}$ Temperature of gas entering the combustor $\left({ }^{\circ} \mathrm{C}\right)$

\section{Pressure Drop Parameters}

\begin{tabular}{ll|ll}
$A_{\mathrm{c}}$ & HRSG cross section area $\left(\mathrm{m}^{2}\right)$ & $A_{\mathrm{s}}$ & HRSG total surface area $\left(\mathrm{m}^{2}\right)$ \\
$d$ & Recycling pipe diameter (m) & $D$ & HRSG tube diameter (m) \\
$D_{\mathrm{h}}$ & Hydraulic diameter (m) & $\Delta T_{l m}$ & Log mean temperature difference \\
$\Delta P_{H R S G}$ & HRSG pressure drop (Pa) & $\Delta P_{\text {pipe }}$ & Recycling pipe pressure drop (Pa) \\
$\epsilon$ & Wall roughness (m) & $\mathrm{f}$ & Friction factor \\
$F$ & $\Delta T_{l m}$ correction factor & $H$ & HRSG height (m) \\
$k$ & Thermal conductivity of flue gas & $L$ & HRSG length (m)
\end{tabular}




\begin{tabular}{|c|c|c|c|}
\hline$L_{\text {pipe }}$ & $\begin{array}{l}\text { Recycling pipes equivalent length } \\
\text { (m) }\end{array}$ & $\dot{m}$ & Flue gas flowrate $(\mathrm{kg} / \mathrm{s})$ \\
\hline$\mu$ & Dynamic viscosity $(\mathrm{kg} / \mathrm{m} . \mathrm{s})$ & $\mathrm{N}$ & $\begin{array}{l}\text { Number of tube rows along HRSG } \\
\text { length }\end{array}$ \\
\hline $\mathrm{Nu}$ & Nusselt Number & $\dot{Q}_{H R S G}$ & Total transferred duty in HRSG (W) \\
\hline $\operatorname{Re}$ & Reynolds number & $\rho$ & Density $\left(\mathrm{kg} / \mathrm{m}^{3}\right)$ \\
\hline$S_{\mathrm{L}}$ & HRSG longitudinal pitch (m) & $S_{\mathrm{T}}$ & HRSG transverse pitch $(\mathrm{m})$ \\
\hline$U$ & $\begin{array}{l}\text { HRSG overall heat transfer coeffi- } \\
\text { cient }\left(\mathrm{W} / \mathrm{m}^{2} \mathrm{~K}\right)\end{array}$ & $V$ & Bulk flue gas velocity $(\mathrm{m} / \mathrm{s})$ \\
\hline$V_{0}$ & $\begin{array}{l}\text { Average gas velocity at HRSG en- } \\
\text { trance }(\mathrm{m} / \mathrm{s})\end{array}$ & $V_{\max }$ & $\begin{array}{l}\text { Maximum gas velocity in HRSG } \\
(\mathrm{m} / \mathrm{s})\end{array}$ \\
\hline$W$ & HRSG width (m) & & \\
\hline
\end{tabular}

\section{Introduction}

Herein, the pressurized oxycoal combustion process presented in Figure 1, and widely described in [1, 2, 3, 4], is optimized for variable thermal loading. The operation of a power plant is subject to variations in the imposed operating conditions. For example, uncertainties in the fuel characteristics, ambient conditions, and input streams specifications alter the behavior of the power plant and may cause the plant to have significantly lower performance compared to nominal operation. Such uncertainties are studied for the oxycoal combustion process in [5]; therein, an optimization formulation resulted in an ideally flexible design that achieves the maximum possible performance of the process at any set of the uncertain parameters.

Another very important disturbance to the process is variable loading, and is considered herein. At the time of plant design, the loading in uncertain. Load variations as well as uncertainty in load is increasing in importance, $[6,7]$, especially with the rise of the renewable but intermittent electric energy production, particularly wind and solar. Therefore, because the process in not always operating at nominal conditions, it is crucial to design the process for an overall maximum performance, rather than the maximum performance at nominal conditions; in general, this is very challenging and exhibits strong tradeoffs.

Studies regarding the performance of power generation processes at partload are available in literature particularly for gas cycles and combined cycles, where significant achievements in the design of the gas turbines allow them to operate flexibly to load variations, $[8,9]$. Fewer studies of partload are available for Rankine cycles or the bottoming cycle of a combined cycle. In [6] a combined cycle is addressed to obtain high performance at partload and meet the emissions criteria because of the efficiency decrease with the decrease in operation load; the addressed parameters for optimization are those related to the gas process where the gas turbines are fitted with guiding vanes and preheating of the gas cycle air improve the overall efficiency at partload. However, the 
parameters of the Rankine cycle itself are not addressed. Similarly pertaining to the gas cycle section of the combined cycle, [10] addresses the importance of guiding vanes and [11] studies different types of commercial gas turbines, while maintaining the conditions for the bottoming Rankine cycle at nominal in order to prevent alterations in its behavior. Solar thermal power generation and organic Rankine cycles are also studied under the influence of partload, [12], therein however, the Rankine cycle design and operation are not considered but rather the size of the solar field for the minimum levelized cost of electricity production for a given load schedule. Optimal time-variable operation is also considered for solar thermal in $[13,14,15]$ and for hybrid solar-fossil plants in [16] to account for the variation of solar insolation and electricity prices. Judes and Tsatsaronis [17] presents a comprehensive study of a simplified single-pressure combined cycle power plant under variable loading; therein, the main variables are the choice of the gas turbines and the temperature approach of the heat recovery steam generators. The Rankine cycle is a simple two-stage turbine with no reheat or regeneration. As will be demonstrated in this study, regeneration and thermal recovery of a complex Rankine cycle have a complex behavior and require a dedicated evaluation. Other studies involving the partload flexibility of the Rankine cycle deal with comparing the valve throttling method to sliding pressure boilers method for partload operations, or even hybrid methods combining both, $[18,19,20]$. However, the optimal design and operation of the process are not addressed as herein.

The first challenge in the analysis of load variations is determining the steam turbine expansion line behavior as the operation deviates from the nominal conditions. Experimental isentropic efficiency data are first analyzed in Section 2 to determine the expansion line behavior and performance curves. Then, Section 3 presents the modeling approach. The change of load also requires changes in several parameters to satisfy the operating requirements of the units. For instance, the requirement on excess oxygen in combustion implies that the oxygen stream is proportional to the coal stream. Moreover, for realistic representation of the process, the pressure losses in the heat recovery steam generator (HRSG) and in the recycling pipes are evaluated and implemented. Then, the optimization formulation is presented in Section 4, i.e., optimizing the process at different loads (100\% to $30 \%$ with $10 \%$ increments) taking care in modeling the design variables particularly the bleeds' extraction pressures. Following proven thermodynamic criteria of optimum design and operation, [21, 22, 23, 24], active constraint optimization is utilized to simplify the optimization problem and avoid convergence to suboptimal local optima. Finally, results are presented in Section 5 where the importance of optimization is reflected by the significant performance improvement of the variable load operations. Moreover, the flexibility of the process to partload is evaluated by comparing the performance of a fixed design over the range of loads to the maximum possible performance; the latter is the performance of the processes designed for each of the specific loads. In designing for a specific load, the turbines are considered to allow for the whole range of load operations, thus having the nominal design, as justified in Section 4. Results show that due to the recovery section, the process is ideally flexible to variable load, i.e., a fixed design operating at variable load matches the maximum possible performance 
$\overline{\text { for each load under a suitable assumption for the air separation unit (ASU). In contrast, Rankine cycles without }}$ pressurized recovery do not share this favorable property. Other important benefits of the recovery section are explained.

\section{Turbine Performance Curves}

The thermal load (TLoad) is the ratio of the coal flowrate into the combustor to that of the full load nominal operation (TLoad $=\frac{\dot{m}_{\text {coal actual }}}{\dot{m}_{\text {coal, nominal }}}$. As the thermal load changes, the amount of thermal energy transported from the flue gas to the working fluid of the Rankine cycle changes, thus changing the behavior of the working fluid. The deviation of the turbine operation from the nominal conditions changes their efficiency and power output. Therefore, an accurate representation of the expansion line versus the relevant variations in the process is required. Stodala, [25], is credited for one of the earliest attempts to assess the flow variations of a multistage turbine by developing the "ellipse law" using experimental data. This rule is an experimentally derived equation that relates the steam mass flowrate, inlet and outlet pressures, and inlet temperature at off-design modes. Here however, the efficiency and power output of the turbine are also required. Therefore, the off-design operation and performance of the steam turbine is obtained by a different approach. Backed by experimental data, Table 1, and rules of current practice, [26], it is well known that in an off-design operation of a steam turbine the volumetric flowrate profile of the steam has to be identical to the nominal volumetric flowrate profile. The reasons and implementation of this approach are detailed next.

Experimental data from a standard Rankine cycle without carbon capture and sequestration (CCS), with power ratings similar to those of the pressurized OCC process, are shown in Table 1. The specifications of the working fluid and the response of each of the turbines are shown for different thermal loading. The presented operations are not necessarily optimal, but the efficiency of the expansion line for the particular values of the working fluid conditions at the inlet of each turbine can be obtained from the table.

In general, the exergy of the thermal energy transferred from the flue gas to the working fluid increases with increasing temperature of the working fluid. Therefore, it is favorable to maintain the main stream and the reheat stream temperature at the highest possible value, $600^{\circ} \mathrm{C}$ and $610^{\circ} \mathrm{C}$ respectively; moreover, this implies that the inlet temperatures of the turbines are at their nominal values. Now in order to maintain the temperature of the working fluid at the exit of the HRSG/inlet of the HPT and IPT constant despite the decrease in the thermal load, the mass flowrate of the working fluid has to decrease as seen in Table 1.

Higher pressures of the working fluid increase the exergy of the process, however, the characteristics of the turbine expansion line necessitates decreasing the working fluid pressure with the decrease in thermal load. More specifically, turbines must maintain an approximately constant flow pattern for an efficient and reliable operation, [26], where steam flows smoothly over the blades' surfaces rather than colliding with them. The turbine angular velocities and thus the blades velocities are constant besides during startup and shutdown. Therefore, for 
fixed blades design, to achieve the constant design flow pattern, a constant volumetric flowrate of the working fluid through any section of the turbine is required; note that the volumetric flowrate of the working fluid increases as the steam expands through the turbine. Variations in the volumetric flowrate profile result in deterioration of the lifetime and efficiency of the turbines. To achieve constant volumertic flowrate profile at reduced mass flowrate, the inlet pressures of the turbines are decreased. This can be achieved by i) a constant pressure at the steam generation followed by throttling at the turbine inlet or ii) so-called sliding pressure boiler, i.e., variable pressure at the steam generation, [27, 28]. Herein, it is assumed that the HRSG generates steam at sliding pressure. In the data of Table 1, the volumetric flowrate of the working fluid at both the inlet and exit of the turbines is constant for different loads except for exit of the low-pressure turbine which is maintained at the nominal pressure of the condenser. To achieve this in modeling, the inlet and outlet pressures of the high pressure and intermediate pressure turbines are taken as function of the working fluid mass flowrate. In other words, the equation $\dot{V}=\dot{m} \times v(P, T)=$ constant is enforced at the inlet and outlet of each turbine section, where $\dot{V}$ and $v$ are the total volumetric flowrate and the specific volume, respectively, while $\dot{m}, T \& P$ are the mass flowrate, temperature, and pressure of the working fluid. The temperature is fixed at the inlet, as explained above, and is a dependent variable throughout the expansion process. Thus, the pressure and the mass flowrate are no longer independent resulting in a single degree of freedom in the above equation. Herein, the mass flowrate is chosen as the degree of freedom, for numerical reasons. The mass flowrate is an optimization variable and its value is determined by energy balance during optimization of each thermal load. For each turbine section, the efficiency ratio, the inlet pressure ratio, and the outlet pressure ratio are mapped versus the mass flowrate ratio, wherein each ratio is taken relative to the nominal. With very high accuracy, the inlet and outlet pressure ratios are affine linear functions of the mass flow ratio, as a direct consequence of the physical properties of the water particularly in the very superheated state after the reheat where temperature is relatively high and pressure is relatively low. The efficiency ratio is considered as a piecewise linear function versus the working fluid mass flowrate ratio because it does not seem to follow any particular continuous function versus the mass flowrate ratio.

\section{Modeling Approach}

\subsection{Flowsheet Description}

Similar to [5, 21, 22], the model is implemented in AspenPlus. Figure 1 represents the process where a surface heat exchanger (RHE) is used for sensible and latent heat recovery from the water in the flue gas. The variables and constraints on Figure 1 are used for optimization.

First, an ASU delivers the oxygen stream, which is compressed to the required operating pressure. The oxygen stream is mixed with a primary recycling flue gas stream in order to control the temperature of combustion in the combustor at $1550^{\circ} \mathrm{C}$. Coal is mixed with water to form coal water slurry and fed into the combustor. Adding water to the combustor reduces the efficiency of the process by decreasing the exergy (water acquires thermal 
Table 1: Operating conditions of working fluid and turbine expansion line at different loads. Each turbine operates at a constant volumetric flowrate profile (constant volumetric flowrate at each section of the expansion line). The outlet pressure of the LPT, condenser pressure, is constant and equal to 0.042 bar for the assumed wet cooling condenser

\begin{tabular}{|c|c|c|c|c|c|}
\hline Thermal Load \% & $\mathrm{P}_{\text {inlet }}$ bar & inlet temperature ${ }^{\circ} \mathrm{C}$ & $\frac{\dot{m}_{\mathrm{FW}, \text { actual }}}{\dot{m}_{\mathrm{FW}, \text { nominal }}}$ & $\frac{\eta_{\text {actual }}}{\eta_{\text {nominal }}}$ & $\frac{P_{\text {inlet }}}{P_{\text {outlet }}}$ \\
\hline \multicolumn{6}{|c|}{ High-Pressure Turbine (HPT) } \\
\hline 100 & 250 & 600 & 100 & 100 & 4.2888 \\
\hline 70 & 169.93 & 600 & 64.7 & 99.44 & 4.177 \\
\hline 50 & 120.14 & 600 & 45.6 & 99.33 & 4.093 \\
\hline 35 & 84.62 & 600 & 32.0 & 98.20 & 4.058 \\
\hline \multicolumn{6}{|c|}{ Reheat - Intermediate-Pressure Turbine(IPT) } \\
\hline 100 & 52.90 & 610 & 100 & 100 & 5.204 \\
\hline 70 & 36.91 & 610 & 69.8 & 98.75 & 4.981 \\
\hline 50 & 26.55 & 610 & 50.3 & 98.75 & 4.804 \\
\hline 35 & 18.95 & 610 & 35.8 & 98.75 & 4.683 \\
\hline \multicolumn{6}{|c|}{ Low-Pressure Turbine(LPT) } \\
\hline 100 & 10.44 & - & 100 & 100 & 239.535 \\
\hline 70 & 7.60 & - & 72.9 & 99.25 & 174.419 \\
\hline 50 & 5.67 & - & 53.9 & 98.18 & 130.233 \\
\hline 35 & 4.15 & - & 39.3 & 96.79 & 95.349 \\
\hline
\end{tabular}


energy from a high-temperature source, but the majority of this thermal energy is recovered at the low-temperature section during flue gas condensation), [21]. However, to be able to feed the fuel into the combustor at the required elevated pressure, and in order to allow for the operation of the Isotherm ${ }^{\circledR}$ combustor, [29], coal water slurry is required instead of pulverized coal. The combustion gas is mixed with a secondary recycling stream to control the temperature of the hot gas entering the $\mathrm{HRSG}$ at $800^{\circ} \mathrm{C}$ as dictated by the metallurgic properties of the convectivedominant heat exchanger, $[1,2,3,4,32,21]$. At the HRSG, the thermal energy is transferred from the flue gas to the working fluid of the Rankine cycle. Most of the cool gas exiting the HRSG is recycled for the temperature control processes, and the non-recycled portion proceeds for the thermal recovery at the RHE before proceeding to the carbon sequestration unit CSU. The flue gas is predominantly $\mathrm{CO}_{2}$ and $\mathrm{H}_{2} \mathrm{O}$; the latter is easily separated by condensation allowing for an easier sequestration of the carbon rich gas in the CSU.

As the pressure of the flue gas increases, the partial pressure of water vapor in the flue gas increases, therefore, condensation of the water vapor in the flue gas occurs at higher temperatures. Earlier and higher-temperature condensation of the water vapor of the flue gas in the RHE allows to recover more thermal energy from the flue gas and with a higher exergy, [21]; at a low operating pressure, the pinch in the HRSG is encountered at the onset of water condensation in the flue gas, which limits the amount of recovered thermal energy because the flue gas exits the RHE at a relatively large temperature with a relatively large moisture content. Increasing the pressure increases the condensation temperatures and increases and alleviates the limitations of the pinch, allowing for more thermal energy transfer. Moreover, there are numerous other benefits for having a pressurized flue gas system which are not only specific to the OCC process, for example compared to the atmospheric process a pressurized process has an order of 10 larger overall heat transfer coefficient in the HRSG, faster boiler load response, increase boiler efficiency and eliminate air leakage, etc. $[34,35,36,37,38,39,40]$. On the other hand, for a the preferred thermoeconomical design criteria of the HRSG and the recycling pipes shown in Section 3.3, [21], increasing the pressure increases the pressure losses encountered by the flue gas. The tradeoff between recovery and losses signify the presence of an optimum operation which requires optimization. Special care is taken against acid condensation of the flue gas outside the RHE. The combustion of coal results in nitric and sulfuric oxides, where the acid due point also increases with increasing pressure; therefore, constraints are placed on the flue gas prior to the RHE, in particular cool gas exiting the HRSG and the mixture of oxygen and the primary recycled flue gas are required to be at least $20^{\circ} \mathrm{C}$ above the acid condensation temperature, and the feedwater entering the HRSG is required to be at least $5^{\circ} \mathrm{C}$ above the acid condensation temperature to avoid acid condensation on the feedwater tubes.

The Rankine cycle is a single-reheat, supercritical steam cycle with regeneration. Only two closed and one open (deaerator) feedwater heaters are used; the thermal recovery substitutes for low-pressure feedwater heaters, $[21,22]$. The steam expansion line has five extractions, one for each of the three regeneration bleeds, the reheat stream, and the atomizer stream for the combustor. Table 2 shows the fixed parameters of the process. 
Figure 1: Oxycombustion cycle flowsheet based on wet recycling. Note that this schematic does not represent entirely the modeling, e.g., turbines were modeled with multiple sections in AspenPlus ${ }^{\circledR}$

\subsection{Process Operating Parameters}

The analysis of the process is done in pseudo-steady state, i.e., does not consider the transition dynamics between different power levels. For the scope of the current work, the ASU is accounted for by its power requirements and is not modeled rigorously. Operating the ASU at partload is likely to increase the specific power requirement for producing the oxygen stream, i.e., the the amount of energy consumed per unit mass of $\mathrm{O} 2$ provided. However, herein the specific power demand and specifications of the ASU are considered constant (for any design and operation). A simple justification of the assumption is that oxygen storage allows the ASU to work at the optimal point and thus constant specific power consumption irrespective of partial load. If storage is not practical, the ASU is still required to have the full-load design; in that case finding the efficiency as a function of oxygen flowrate would require a detailed model, but would not change anything in the analysis of this manuscript. In particular, the comparison of the flexible design to the dedicated designs will not be affected, which is the aim of this study. In conclusion, the specific power demand and specifications of the ASU are considered constant for any design and operation without affecting the conclusions of flexibility to the thermal load.

Table 2 shows the fixed parameters of the process, pertaining to the operation of the Isotherm ${ }^{\circledR}$ combustor, [29], and other components. To satisfy these while varying the load requires adjustments to several streams in order to satisfy the operation requirements. First of all, changing the thermal load requires a change in the amount of coal and thus the amount of slurry water needed to transport the coal keeping the required water ratio in the coal water slurry mixture. Moreover, the amount of oxygen required to oxidize the fuel also changes, and therefore, the air flowrate entering the air separation unit changes. Also, the amount of the atomizer stream needed to atomize the coal water slurry entering the combustor changes. In the Rankine cycle, the steam leaks from the turbines are assumed to scale linearly with the working fluid flowrate. Now that the atomizer stream flowrate, which is extracted from the steam expansion line, and the turbine leaks change, the amount of makeup water also changes. All of the dependent variations are modeled in calculator blocks or design specifications in order to maintain the operation constraints of the process at any load.

\subsection{Flue Gas Pressure Losses}

Another important aspect of the model is the calculation of the flue gas pressure losses as it passes through the HRSG and the recycling pipes. Pressure losses are calculated by utilizing standard pressure loss equations [30, 31], and similarity analysis $[5,21,22]$. The losses depend on the designs of the HRSG and the recycling pipes, which depend on the process design pressure and economical considerations [21]. Therefore, at a given thermal load, the pressure drops depend on whether the HRSG and pipes are designed for that specific load, or are operated at a load different than their design load. In the case of the former, the process pressure and the HRSG and pipe 
Table 2: Fixed simulation parameters

\begin{tabular}{lc}
\hline \hline Simulation-Parameter Name & Parameter Value \\
\hline \hline Coal & \\
\hline Coal HHV & $31.09 \mathrm{MJ} / \mathrm{kg}$ \\
Coal LHV & $29.88 \mathrm{MJ} / \mathrm{kg}$ \\
Proximate analysis (moisture-excluded basis except for moisture content) \\
Moisture & 6.4 \\
FC & 57.158 \\
VM & 35.363 \\
Ash & 7.479 \\
& \\
Ash & \\
Carbon & 7.479 \\
Hydrogen & 75.962 \\
Nitrogen & 5.021 \\
Chlorine & 1.282 \\
Sulfur & $0.37 \mathrm{~kJ} / \mathrm{kg}$ \\
Oxygen & $29.73^{\circ} \mathrm{C}$ \\
\hline Slurry water input mass fraction & \\
Steam/coal weight ratio of atomizer stream & $30 \mathrm{bar}$ \\
Atomizer stream pressure at nominal condition & $95 \%$ \\
ASU's oxygen purity molar fraction & 3.722 \\
\hline Oxygen molar fraction in flue gas & $3.48 \%$ \\
\hline
\end{tabular}




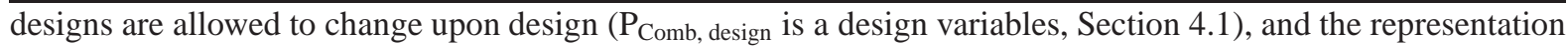
of the pressure losses are identical to those of [21]:

\section{Design specific for a particular load}

For the recycling pipes upon design:

$$
\Delta P_{\text {pipe }}=\rho f \frac{L_{p}}{d} \frac{V^{2}}{2}
$$

where $V$ is the bulk gas velocity in the pipe, $d$ is the pipe diameter, $L_{p}$ is the pipe equivalent length, $\rho$ is the gas density, and $f$ is the friction factor calculated by

$$
f_{\text {pipe }}=\left\{-2.0 \log \left[\frac{(2 \epsilon / d)}{7.4}-\frac{5.02}{\operatorname{Re}_{d}} \log \left(\frac{(2 \epsilon / d)}{7.4}+\frac{13}{\operatorname{Re}_{d}}\right)\right]\right\}^{-2}
$$

where $\epsilon$ is the pipe roughness, $\operatorname{Re}_{d}=\frac{\rho V d}{\mu}$ is the Reynolds number based on the pipe diameter, $\rho$ is the flue gas density, and $\mu$ is the dynamic viscosity of the gas.

The pipe diameter, $d$, and the gas velocity, $V$, are related by $\dot{m}=\rho V \frac{\pi d^{2}}{4}$, where $\dot{m}$ is the recycled gas mass flowrate through each of the two pipes. Note that for practical considerations the pipes diameters and the gas velocities in the pipes have to fall within fixed ranges. The acceptable ranges are shown in Table 3 similar to those considered $[32,21]$. The equivalent length is obtained by considering a $63.5 \mathrm{mbar}$ pressure drop in each pipe at an operating pressure of 10 bar based on experimental data from ENEL.

Table 3: Recycling pipes diameters and gas velocity ranges, [32, 21]

\begin{tabular}{ccc}
\hline \hline & Diameter Range $(\mathrm{m})$ & Velocity Range $(\mathrm{m} / \mathrm{s})$ \\
\hline \hline Primary Recycling Pipe & {$[1-6]$} & {$[4-25]$} \\
Secondary Recycling Pipe & {$[1-4.15]$} & {$[14-30]$} \\
\hline
\end{tabular}

The larger the pipe diameter, the smaller the gas flow velocity, and the smaller the pressure drop. Thus, a larger pipe is always favored in terms of efficiency but not necessarily from an economical point of view as the capital, installation, and maintenance costs would increase. However, very large flow velocities can cause structural failure and acoustic resonance. Herein, at each iteration within the optimization study, the largest allowable diameter, for each of the two pipes, is chosen such that the gas velocity remains within the velocity range. In the case that the flowrate is too high, the upper bound on the diameter is chosen and the velocity range is violated.

For the HRSG upon design:

$$
\frac{\Delta P_{H R S G, a}}{\Delta P_{H R S G, b}}=\frac{\dot{Q}_{\mathrm{HRSG}, \mathrm{a}} \rho_{\mathrm{a}}^{2} \dot{m}_{\mathrm{b}}}{\dot{Q}_{\mathrm{HRSG}, \mathrm{b}} \rho_{\mathrm{b}}^{2} \dot{m}_{\mathrm{a}}}
$$

where $\dot{Q}_{\mathrm{HRSG}}$ is the rate of thermal energy transferred in the HRSG, $\dot{m}$ is the flue gas mass flowrate, and a and b stand for actual design and basecase design respectively. 
Operation with a fixed design

On the other hand, when the process operates at a load while designed for a different load, the specifications of the HRSG and the recycling pipes are identical to those of the design load. Moreover, the design pressure is the maximum allowed pressure of any operation. The losses are computed based on similarity analysis between the actual, a, and design, $\mathrm{d}$, operating conditions:

The recycling pipes

$$
\frac{\Delta P_{\text {pipe, a }}}{\Delta P_{\text {pipe, }}}=\frac{\left(\rho f \frac{L_{p}}{d} \frac{V^{2}}{2}\right)_{\mathrm{a}}}{\left(\rho f \frac{L_{p}}{d} \frac{V^{2}}{2}\right)_{\mathrm{d}}}=\frac{\left(f \frac{L_{p}}{d^{3}} \frac{\dot{m}^{2}}{\rho}\right)_{\mathrm{a}}}{\left(f \frac{L_{p}}{d^{3}} \frac{\dot{m}^{2}}{\rho}\right)_{\mathrm{d}}}=\frac{f_{\mathrm{d}} \dot{m}_{\mathrm{a}}^{2} \rho_{\mathrm{d}}}{f_{\mathrm{a}} \dot{m}_{\mathrm{d}}^{2} \rho_{\mathrm{a}}}
$$

The pipes lengths, $\mathrm{L}_{\mathrm{p}}$, and the pipes diameters, $d$, are constant and equal to those of the design load, therefore, do not appear in the final expression.

For the HRSG:

$$
\begin{aligned}
\frac{\Delta P_{\mathrm{HRSG}, \mathrm{a}}}{\Delta P_{\mathrm{HRSG}, \mathrm{d}}} & =\frac{\left(f N \rho \frac{V_{\max }^{2}}{2}\right)_{\mathrm{a}}}{\left(f N \rho \frac{V_{\max }^{2}}{2}\right)_{\mathrm{d}}}=\frac{\left(f \rho V_{0}^{2}\right)_{\mathrm{a}}}{\left(f \rho V_{0}^{2}\right)_{\mathrm{d}}} \\
& =\frac{\left(f \rho\left(\frac{\dot{m}}{\rho A_{\mathrm{c}}}\right)^{2}\right)_{\mathrm{a}}}{\left(f \rho\left(\frac{\dot{m}}{\rho A_{\mathrm{c}}}\right)^{2}\right)_{\mathrm{d}}}=\frac{\left(f \frac{\dot{m}^{2}}{\rho}\right)_{\mathrm{a}}}{\left(f \frac{\dot{m}^{2}}{\rho}\right)_{\mathrm{d}}} \\
& \approx \frac{\dot{m}_{\mathrm{a}}^{2} \rho_{\mathrm{d}}}{\dot{m}_{\mathrm{d}}^{2} \rho_{\mathrm{a}}}
\end{aligned}
$$

The HRSG design and size are invariant same as those of the design load), therefore, the number of rows $N$, and the cross sectional area $A_{\mathrm{c}}$, are constant. Moreover, the tube diameters $D$, the transverse and longitudinal distance between the tubes $S_{\mathrm{T}} \& S_{\mathrm{L}}$, are also constant leading to $\frac{V_{\max , a}}{V_{\max , \mathrm{d}}}=\frac{V_{0, \mathrm{a}}}{V_{0, \mathrm{~d}}} . f$ is the friction factor, which is approximately constant for the ranges of Reynolds numbers involved. The pressure losses at a given operation load are inversely proportional to the density of the flue gas. In other words, optimization of operation while the process is designed for a different load results in the maximum allowable value of the operating pressure, since it decreases pressure losses and does not decrease thermal recovery; also the tradeoff between the $\mathrm{O}_{2}$ and the $\mathrm{CO}_{2}$ compression is insensitive within those ranges of pressures. However, since the operation pressure cannot exceed the design pressure of the design load, the optimum operating pressure is expected to be equal to the design pressure; this is verified by the results.

\section{Optimization Formulation}

The objective of the study is to achieve a high performance for the pressurized OCC process subject to variable loading. In particular, it is first desired to determine the flexibility of the process. If the performance of the process designed for the nominal load but operating at a different load is lower than the performance of the process designed specifically for the non-nominal load, then the process is not ideally flexible. In that case, the 
original design needs to be revisited, such that a maximum overall performance is achieved rather than maximum performance at nominal conditions. To examine the ideal flexibility, two families of optimization processes are required over the range of possible thermal load; first, optimization of operation under the nominal design, and second, simultaneous optimization of design and operation at the specific thermal load. Similar to the study of uncertainties at nominal loading, [5], a classification of the optimization variables as design and as operation is required. Operation variables can change with load variations, whereas, design variables are fixed. As described in Section 4.2, load variations impose additional constraints compared to nominal operation

As mentioned above, the redesign of the process for a specific load is considered to allow for the same range of load operation; therefore, the turbines are ones that can accommodate the nominal load operation, without reaching unrealistic working fluid pressures, thus have the nominal load design. Recall that an expansion line design requires maintaining the design flow pattern for maintaining high turbine performance and reliability. More specifically, the turbines' inlet pressures and pressure ratios are adjusted as a function of the working fluid flowrate in order to maintain the fixed volumetric flowrate profile of the working fluid in the turbines. Operating at a load lower than the design is possible by decreasing the turbines' inlet pressures and pressure ratios, and vice versa. Conversely, to operate at higher than design load, the pressure would have to be increased. But to achieve high performance at nominal conditions, the pressure is typically set at the maximal allowed limit, thus further increase is not possible. So if the expansion line is designed for a partload operation, then the plant is incapable of providing the initial full load power rating. However, since a power plant is expected to operate for the majority of its lifetime under the initial full load power rating, the full load design of the expansion line is the desired design for any partload.

\subsection{Design and Optimization Variables}

Table 4 characterizes the variables as design or operation and provides their range, and Figure 1 marks the variables on the flowsheet. The basecase default values are the optimized results of the design that is ideally flexible to uncertainties in coal, ambient conditions, and input stream specifications of the process at nominal load [5]. The classification of the variables is similar to that in [5] with few additions and differences. The methodology of implementing active constrains depends on the variables' characterizations and is discussed in Section 4.3

Combustor Pressure, $P_{\text {Comb, o }} \mathcal{E} P_{\text {Comb, } d}$.

As discussed in Section 3.3, the operating pressure of the combustor, $\mathrm{P}_{\mathrm{Comb}, \mathrm{o}}$, is an operation variable, while the upper bound on its range, equal to the design pressure of the design load, $\mathrm{P}_{\mathrm{Comb}, \mathrm{d}}$, is a design variable. It is also seen that for a fixed design, the pressure losses are smaller with increasing operation pressure, and therefore, optimization is expected to choose the maximum allowed value i.e., the design pressure. This is verified by the results. 
Combustor Duty, $\dot{Q}_{\text {Comb }}$.

In [5] where only the nominal load is considered, the duty of the combustor, $\dot{Q}_{\text {Comb }}$, is treated as a design variable. However, the specifications and insulation of the combustor are fixed with the design, and the value of $\dot{Q}_{\text {Comb }}$ for a given design changes with the operating load. At a given design with a $\dot{Q}_{\mathrm{Comb}, \mathrm{d}}$, the resulting actual operational combustor duty, $\dot{Q}_{\mathrm{Comb}, \mathrm{a}}$, is assumed to scale with the design duty according to the ratio of the thermal loads of the design, $d$, and operation, $o$; in other words, $\frac{\dot{Q}_{\mathrm{Comb}, \mathrm{a}}}{\dot{Q}_{\mathrm{Comb}, \mathrm{d}}}=\frac{\mathrm{TLoad}_{\mathrm{a}}}{\mathrm{TLoad}_{\mathrm{d}}}$. Note that the linear dependence is consistent with the extreme cases: for a fixed design, at zero load there is zero transferred duty, and at design load the transferred duty equals to the value at design. Similarly, the range of $\dot{Q}_{\mathrm{Comb}, \mathrm{d}}$ is assumed to depend on the nominal duty $\dot{Q}_{\mathrm{Comb}, \mathrm{n}}$ according the following equation, $\frac{\dot{Q}_{\text {Comb, }}}{\dot{Q}_{\text {Comb, } \mathrm{n}}}=\frac{\mathrm{TLoad}_{\mathrm{d}}}{\mathrm{TLoad}_{\mathrm{n}}}=\frac{\mathrm{TLoad}_{\mathrm{d}}}{1}$.

\section{Feedwater Flowrate, $\dot{m}_{F W, \text { Main }}$.}

The performance curves of the turbines are available as discussed in Section 3. The pressures of the working fluid are set to accommodate the turbine expansion line constraints. The main feedwater flowrate is an operation variable with no restrictions on the range of its variation. It is trivial to deduce that the optimal flowrate decreases with decreasing load. Therefore, bounding the range of the feedwater flowrate from above at the nominal value facilitates the problem without constraining the optimization; a slightly larger upper bound is used nevertheless to make sure that the problem is not constrained.

\section{Bleeds Flowrates, $\dot{m}_{B L D 1,2, \& 3 \text {. }}$}

The bleeds flowrates can, and should, change with different thermal loads since the amount of regeneration required for the varying feedwater flowrate changes. Moreover, the effectiveness of regeneration changes due to the change in the expansion line pressures, as explained later, and require a different optimum flowrate. Therefore, $\dot{m}_{\mathrm{BLD} 1,2, \& 3}$ are considered as operation variables.

\section{Bleeds Pressures, $P_{B L D 1,2, \& 3 \text {. }}$}

In [5], where only the nominal load is considered, the bleeds extraction pressures are fixed with the initial design of the turbine expansion line, representing a fixed position of extraction within a turbine stage, and thus are design variables. Here however, fixed bleed extraction position is not equivalent to fixed extraction pressure since at different loads the pressure ranges of each turbine stage change. Therefore, a fixed extraction position is the required design variable, and this results in different bleed pressures at different loads. Recall that for a given design, the turbines operate with a fixed volumetric flowrate throughout in order to maintain the efficient flow pattern. Therefore, a fixed extraction position is one that has a fixed volumetric flowrate of the working fluid passing through the turbine at the section of extraction.

Modeling the bleed extraction positions by specifying the bleed pressure that satisfy the volumetric flowrate constraint would result in a highly iterative procedure and in an extremely complicated optimization process. 
Fortunately, it is possible to eliminate the need for iteration and reproduce the fixed extraction position by simple formulas. To achieve this, the above iterative procedure is separately implemented on an isolated expansion line, and the results are compared to fixing the ratio of the extraction pressure relative to the inlet and the outlet turbine pressures. The comparison is performed over a range of the working fluid flowrate, representing a range of operation load. At the range of interest, keeping the simple ratio of bleed extraction pressure, namely $\frac{P \text { extraction- } P \text { outlet }}{P \text { inlet }-P \text { outlet }}$ as constant over a range of $100 \%$ to $30 \%$ load, results in less than a $0.5 \%$ difference in the volumetric flowrate of the working fluid at the point of extraction. This implies that keeping the pressure ratio fixed according to the dimentionless variable proposed, corresponds to a fixed extraction position. Keeping the pressure ratio fixed is easy to implement and makes optimization tractable.

\section{Extraction Stage, Integer Variables.}

Similar to $[21,22,5]$, integer variables are used to select the extraction stage, where each stage has different ranges of operation and different performance properties. The discrete variables representing the extraction stage are also design variables.

\section{FWH Duty Transfer, $\dot{Q}_{F W H I \& 2}$.}

The duty transfer within each FWH is an operation variable.

\section{Deaerator Pressure, $P_{\text {Deaerator }}$.}

The deaerator operating pressure is an operation variable determined primarily by the low-pressure pump delivery pressure and the deaerator bleed pressure at destination. Due to load variation the bleeds' pressures are not constant, and thus the deaerator pressure is subject to change. However, upper and lower bounds on the deaerator pressure should be respected. A deaerator operating temperature range of 101 to $200^{\circ} \mathrm{C}$ is common practice [33]. This temperature range is equivalent to a pressure range of 1.076 to 15.55 bar. In other words, the pressure should be higher than atmospheric (1.013bar), and lower than 15.55bar, the pressure of the maximum allowed saturation temperature of $200^{\circ} \mathrm{C}$, which is a material constraint. Regarding the low-pressure feedwater pump, the pressure range of 5-15 bar obtained in the results, Section5, is considered within the acceptable range of operation. To achieve variable pressure, a variable-speed driven (VSD) pump could be utilized. If instead a fixed-pressure pump is utilized, then the pressure of the low-pressure pump can be set to around 15 bar (maximum pressure required for any operating load, Section 5) and the feedwater would be throttled into the deaerator tank (if and when needed). The power requirement increase due to always operating at $15 \mathrm{bar}$ is minor, less than 0.01 percentage points change in efficiency of the cycle, because the pumping requirements are relatively low.

\section{Temperature of Flue Gas Exiting the RHE, $T_{F G-R H E-o u t}$.}

The temperature of the flue gas exiting the RHE, $T_{F G-R H E-\text { out }}$, is also an operation variable dictating the amount of recovered thermal energy. However, the optimal value is not expected to vary with different operating loads 
because the optimum flue gas operating pressure is high enough to allow the pinch point to occur at the flue gas exit from the RHE. This expectation is confirmed by the obtained results. Note that even if the value of $\mathrm{T}_{\text {FG-RHE-out }}$ is invariant, the amount of recovered thermal energy at the RHE, $\dot{Q}_{\mathrm{RHE}}$, changes because different loads have different flue gas flowrates and different amounts of energy to recover.

\section{Additional Integer Variables Required for Partload Optimization.}

Finally the process has three additional binary variables, each denoting the activation or deactivation of a bleed flow. In principle, deactivating the bleed flow is identical to setting the bleed flow to zero, however, the binary variables are required for modeling purposes: zero flowrates cause convergence and mass balance errors in AspenPlus. The three integer variables are BLD\#_flow, one for each bleed, and are operation variables, i.e., can be activated depending on the load. Physically these variables are controlled in the same manner the bleed flow is controlled.

\subsection{Constraints}

Constraints on the admissible design and operation are imposed based on physical, practical, and economical considerations. The turbines' volumetric flowrate profile is a major constraint which is satisfied by automating the turbines' inlet pressures and pressure ratios. Twelve constraints are accounted for explicitly at any operation load. The constraints are listed in Table 5 and illustrated in Figure 1. Further, active constraints presented in Section 4.3 allow satisfying the constraints at the simulation level, while providing optimal performance.

\subsection{Active Constraint Optimization}

In $[21,23,24]$ it is proven that optimal operating conditions occur at some active constraints. Enforcing these constraints as operation specifications, facilitates the optimization in several aspects: i) avoid constraints violations, ii) avoid simulation errors and failures, iii) accelerate convergence, iv) avoid convergence to suboptimal local optima. The desired active constraints can be satisfied at the simulation level by manipulating the main influencing variables.

The following constraints and variables are coupled:

1. $\mathrm{MITA}_{\mathrm{HRSG}} / \dot{m}_{\mathrm{FW}, \text { Main }}$ : The allowed minimum internal temperature approach constraint on the HRSG is achieved by manipulating the main feedwater flowrate

2. $\mathrm{MITA}_{\mathrm{RHE}} / \mathrm{T}_{\mathrm{FG}-\mathrm{RHE}-\mathrm{out}}$ : The allowed minimum internal temperature approach on the RHE achieved by manipulating the temperature of the flue gas exiting the RHE

3. \& 4. Double-pinch FWH(1\&2)/ $\dot{Q}_{\mathrm{FWH}(1 \& 2)}$ and $\dot{m}_{\mathrm{BLD}(1 \& 2)}$. Both the duty transfer within each closed FWH and the flowrate of the respective bleeds are utilized in order to guarantee equal values of the temperature approach at the feedwater heater outlet, and at the position of phase change of the bleed, [23, 24]. Note that the areas of the feedwater heaters are fixed and thus the value of the double-pinch is not necessarily equal at different loads: 
Table 4: Design And Operation Variables. The integer variables BLD_flow inhibit or allow a bleed flow; inhibiting a flow by a BLD_flow value of zero is, in practice, equivalent to setting $\dot{m}_{\mathrm{BLD}}$ to zero, but required here for modeling purposes

\begin{tabular}{|c|c|c|c|}
\hline Number & Variable & Range & Variable Type \\
\hline 1 & $\mathrm{P}_{\mathrm{Comb}, \text { operation }}$ & {$\left[1-\mathrm{P}_{\mathrm{Comb}, \text { design }}\right]$ bar } & Operation \\
\hline 2 & $\mathrm{P}_{\mathrm{Comb}, \text { design }}$ & {$[1-10]$ bar } & Design \\
\hline 3 & $\dot{Q}_{\mathrm{Comb}}$ & {$[1-30] \times$ TLOAD MW } & Design \\
\hline 4 & $\dot{m}_{\mathrm{FW}, \text { Main }}$ & {$[20-300] \mathrm{kg} / \mathrm{s}$} & Operation \\
\hline 5 & $\begin{array}{l}\text { BLD1_stage integer vari- } \\
\text { able }\end{array}$ & Stages: $1-4$ & Design \\
\hline 6 & 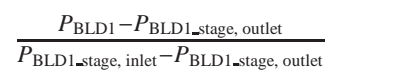 & {$[0-1]$} & Design \\
\hline 7 & $\dot{m}_{\mathrm{BLD} 1}$ & {$[0-60] \mathrm{kg} / \mathrm{s}$} & Operation \\
\hline 8 & $\begin{array}{l}\text { BLD2_stage integer vari- } \\
\text { able }\end{array}$ & Stages: 3-6 & Design \\
\hline 9 & $\frac{P_{\mathrm{BLD} 2}-P_{\mathrm{BLD} 2 \text { stage, outlet }}}{P_{\mathrm{BLD2} \text {-stage, inlet }}-P_{\mathrm{BLD2} \text { stage, outlet }}}$ & {$[0-1]$} & Design \\
\hline 10 & $\dot{m}_{\mathrm{BLD} 2}$ & {$[0-30] \mathrm{kg} / \mathrm{s}$} & Operation \\
\hline 11 & $\begin{array}{l}\text { BLD3_stage integer vari- } \\
\text { able }\end{array}$ & Stages: $5-7$ & Design \\
\hline 12 & $\frac{P_{\mathrm{BLD} 3}-P_{\mathrm{BLD} 3 \text { stage, outlet }}}{P_{\mathrm{BLD} 3 \text { stage, inlet }}-P_{\mathrm{BLD} 3 \text { stage, outlet }}}$ & {$[0-1]$} & Design \\
\hline 13 & $\dot{m}_{\mathrm{BLD} 3}$ & {$[0-30] \mathrm{kg} / \mathrm{s}$} & Operation \\
\hline 14 & $\dot{Q}_{\mathrm{FWH} 1}$ & [0 - 200] MW & Operation \\
\hline 15 & $\dot{Q}_{\mathrm{FWH} 2}$ & [0 - 200] MW & Operation \\
\hline 16 & $\mathrm{P}_{\text {Deaerator }}$ & {$[2-15.55]$ bar } & Operation \\
\hline 17 & $\mathrm{~T}_{\mathrm{FG}-\mathrm{RHE}-\mathrm{out}}$ & {$[30-200]{ }^{\circ} \mathrm{C}$} & Operation \\
\hline \multicolumn{4}{|c|}{ Required for partload optimization } \\
\hline 18 & $\begin{array}{l}\text { BLD1_flow binary vari- } \\
\text { able }\end{array}$ & $\{0,1\}$ & Operation \\
\hline 19 & $\begin{array}{l}\text { BLD2_flow binary vari- } \\
\text { able }\end{array}$ & $\{0,1\}$ & Operation \\
\hline 20 & $\begin{array}{l}\text { BLD3_flow binary vari- } \\
\text { able }\end{array}$ & $\{0,1\}$ & Operation \\
\hline
\end{tabular}


Table 5: Optimization Constraints, [21,5]. The most challenging constraints are eliminated by setting the bounds on the variables and automating the turbine inlet pressures, turbines pressure ranges, and bleeds extraction pressures, and thus not shown here

\begin{tabular}{|c|c|c|}
\hline Number & Constraint & Value \\
\hline 1 & MITA $_{\text {HRSG }}$ & $\geq 3.7^{\circ} \mathrm{C}$ \\
\hline \multirow[t]{2}{*}{2} & Area $_{\mathrm{FWH} 1}$ & equivalent \\
\hline & & $\mathrm{MITA}_{\mathrm{FWH} 1}=2.1^{\circ} \mathrm{C}$ at nominal \\
\hline \multirow[t]{2}{*}{3} & Area $_{\mathrm{FWH} 2}$ & equivalent \\
\hline & & $\mathrm{MITA}_{\mathrm{FWH} 2}=2.1^{\circ} \mathrm{C}$ at nominal \\
\hline 4 & $\mathrm{q}_{\text {Deaerator }}$ & Saturated Liquid \\
\hline 5 & $\mathrm{P}_{\text {Deaerator }}$ & $\geq 2 \mathrm{bar}$ \\
\hline 6 & $\mathrm{P}_{\text {Deaerator }}$ & $\leq 15.55 \mathrm{bar}$ \\
\hline 7 & $\mathrm{~T}_{\text {Cool-Gas }}$ & $\begin{array}{l}20^{\circ} \mathrm{C} \text { above acid condensation tem- } \\
\text { perature }\end{array}$ \\
\hline 8 & $\mathrm{~T}_{\mathrm{FW}-\mathrm{HRSG} \text {-in }}$ & $\begin{array}{l}5^{\circ} \mathrm{C} \text { above acid condensation tem- } \\
\text { perature }\end{array}$ \\
\hline 9 & $\mathrm{~T}_{\text {Com-Gas-in }}$ & $\begin{array}{l}20^{\circ} \mathrm{C} \text { above acid condensation tem- } \\
\text { perature }\end{array}$ \\
\hline 10 & MITA $_{\text {RHE }}$ & $\geq 7.5^{\circ} \mathrm{C}$ \\
\hline 11 & $\mathrm{CO}_{2-\mathrm{Cap}}$ & $\begin{array}{l}94 \% \text { of total } \mathrm{CO}_{2} \text { produced re- } \\
\text { quired to be captured }\end{array}$ \\
\hline 12 & $\mathrm{CO}_{2} \_\mathrm{Pur}$ & captured $\mathrm{CO}_{2}$ is $96.5 \%$ pure \\
\hline
\end{tabular}


5. $\mathrm{P}_{\text {Deaerator }}$ : For optimal operation, the deaerator pressure has to be equal to the pressure of the deaerator bleed, BLD3, at the deaerator inlet; $[23,24]$. Therefore, $\mathrm{P}_{\mathrm{BLD} 3}$ and $\mathrm{P}_{\text {Deaerator }}$ are coupled to be equal at the level of the deaerator, i.e., after accounting for friction and hydrostatic pressure changes. The deaerator bleed flowrate also plays a role in the optimum value of the deaerator pressure since it affects the amount of pressure loss in the connection pipes

6. qDearator $/ \dot{m}_{\mathrm{BLD} 3}$. The mixture inside the tank deaerator has to reach the saturated liquid state for the effective removal of dissolved air in the working fluid. This constraint is satisfied by the low-pressure bleed to the deaerator

Note that the last two items are relevant only when the deaerator bleed is active, i.e., BLD_flow3 $=1$; otherwise when BLD_flow3=0, the constraint on the quality of the mixture inside the dearator is satisfied by manipulating the deaerator pressure. Moreover, the combustor operation pressure is not equated to the design pressure in an active constraint, in order to show that indeed the optimum operation pressure is the process's design pressure.

\section{Results and Analysis}

Three steps are performed to examine the partload performance of the pressurized OC process. First, a given partload is operated with the nominal design and operating conditions, [5], with changes in the values of the deaerator pressure, feedwater flowrate, and FWHs' duty, in order to satisfy the constraints set on the deaerator pressure and satisfy the FWHs areas. Then, optimization of the operation is performed while keeping the same fixed design. Third, the process is redesigned for that specific partload by simultaneous optimization of design and operation. Recall that the turbine expansion line design is kept fixed in this step, but not the design of the extraction bleeds' positions. The latter optimization obtains the maximum possible performance at that specific load (for the given turbines). Comparing the results of steps two and three, the flexibility of the process to varying load is obtained. The results show that the process is ideally flexible to load variations. The flexibility eliminates the need for a prior knowledge of the operation schedule. The reasons behind the ideal flexibility are shown in Sections 5.2, 5.3 \& 5.4. The comparison of steps 1 and 2 shows that optimization of operation is required even for a flexible design, to achieve high performance. Comparing Steps 2 and 3 shows that a flexible design can match the optimum performance of the process at the evaluated variable loads.

In the case study considered, the lowest thermal load is $35 \%$, see Table 1 . Herein, flexibility assessment is performed om thermal loads reaching down to 30\%, to account for extreme scenarios. Table 6 summarizes the results of [5] which is the ideal flexible design to uncertainties of coal, ambient conditions, and input streams specifications at nominal load, and serves as the basecase of this study. Tables $7 \& 8$ present the results of the flexibility evaluations for the $60 \%$ and $30 \%$ thermal loads, respectively. 
Table 6: Optimal design and operation of the RHE process for coal and ambient conditions variations and FWH area specification, [5]. Results shown are for the coal considered herein

\begin{tabular}{|c|c|}
\hline Fuel Flowrate & $30 \mathrm{~kg} / \mathrm{s}$ \\
\hline Slurry water flowrate & $16.50 \mathrm{~kg} / \mathrm{s}$ \\
\hline Atomizer Stream flowrate & $2.50 \mathrm{~kg} / \mathrm{s}$ \\
\hline Air flowrate & $311.2 \mathrm{~kg} / \mathrm{s}$ \\
\hline Efficiency (based on LHV) & $34.41 \%$ \\
\hline \multicolumn{2}{|c|}{ Independent and Key Dependent Varaibles } \\
\hline $\mathrm{P}_{\mathrm{Comb}}$ & 7.41bar \\
\hline$\dot{Q}_{\mathrm{Comb}}$ & $1 \mathrm{MW}$ \\
\hline$\dot{m}_{\mathrm{FW}}$ Main & $306.0 \mathrm{~kg} / \mathrm{s}$ \\
\hline $\mathrm{P}_{\mathrm{BLD} 1}$ & 99.0bar \\
\hline$\dot{m}_{\mathrm{BLD} 1}$ & $62.22 \mathrm{~kg} / \mathrm{s}$ \\
\hline $\mathrm{P}_{\mathrm{BLD} 2}$ & 26.01bar \\
\hline$\dot{m}_{\mathrm{BLD} 2}$ & $14.69 \mathrm{~kg} / \mathrm{s}$ \\
\hline $\mathrm{P}_{\mathrm{BLD} 3}$ & 16.78bar \\
\hline$\dot{m}_{\mathrm{BLD} 3}$ & $9.27 \mathrm{~kg} / \mathrm{s}$ \\
\hline $\mathrm{P}_{\text {Deaerator }}$ & 14.72bar \\
\hline$\dot{Q}_{\text {FWH1 }}$ & 137.9MW \\
\hline$\dot{Q}_{\mathrm{FWH} 2}$ & 37.70MW \\
\hline $\mathrm{T}_{\text {FG-RHE-out }}$ & $36.9^{\circ} \mathrm{C}$ \\
\hline$\dot{Q}_{\mathrm{RHE}}$ & $122.1 \mathrm{MW}$ \\
\hline \multicolumn{2}{|c|}{ Dependent Variables } \\
\hline $\mathrm{T}_{\text {Cool-Gas }}$ & $327.2^{\circ} \mathrm{C}$ \\
\hline $\mathrm{T}_{\mathrm{FW}-\mathrm{HRSG} \text {-in }}$ & $321.7^{\circ} \mathrm{C}$ \\
\hline $\mathrm{T}_{\text {Comb-Gas-in }}$ & $309^{\circ} \mathrm{C}$ \\
\hline Flue gas fkiwrate in HRSG & $1,138 \mathrm{~kg} / \mathrm{s}$ \\
\hline Condensed water RHE & $33.2 \mathrm{~kg} / \mathrm{s}$ \\
\hline$\Delta P_{H R S G}$ & $0.265 \mathrm{bar}$ \\
\hline$\Delta P_{\text {pipe }}$ Primary & $0.054 \mathrm{bar}$ \\
\hline$\Delta P_{\text {pipe }}$ secondary & 0.035 bar \\
\hline$\dot{m}_{\mathrm{FG}-\mathrm{Rec}-\mathrm{pri}}$ & $281.1 \mathrm{~kg} / \mathrm{s}$ \\
\hline$\dot{m}_{\mathrm{FG}-\mathrm{Rec}-\mathrm{sec}}$ & $736.5 \mathrm{~kg} / \mathrm{s}$ \\
\hline Rankine cycle net power & 409MW \\
\hline $\mathrm{T}_{\text {FW-Recov-out }}$ & $163.5^{\circ} \mathrm{C}$ \\
\hline$P_{\mathrm{HPT}}$ & 250.0bar \\
\hline$P_{\text {Reheat }}$ & 53.5bar \\
\hline
\end{tabular}


Table 7: 60\% thermal load flexibility

\begin{tabular}{|c|c|c|c|}
\hline Variable & $\begin{array}{l}60 \% \text { thermal load sim- } \\
\text { ulation }\end{array}$ & $\begin{array}{l}60 \% \text { thermal load op- } \\
\text { timization of operation } \\
\text { with nominal load de- } \\
\text { sign }\end{array}$ & $\begin{array}{l}60 \% \text { thermal load opti- } \\
\text { mization of design and } \\
\text { operation }\end{array}$ \\
\hline \multicolumn{4}{|c|}{ Input Parameters } \\
\hline Fuel Flowrate & $18 \mathrm{~kg} / \mathrm{s}$ & $18 \mathrm{~kg} / \mathrm{s}$ & $18 \mathrm{~kg} / \mathrm{s}$ \\
\hline Slurry water flowrate & $9.9 \mathrm{~kg} / \mathrm{s}$ & $9.9 \mathrm{~kg} / \mathrm{s}$ & $9.9 \mathrm{~kg} / \mathrm{s}$ \\
\hline Atomizer Stream flowrate & $1.5 \mathrm{~kg} / \mathrm{s}$ & $1.5 \mathrm{~kg} / \mathrm{s}$ & $1.5 \mathrm{~kg} / \mathrm{s}$ \\
\hline Air flowrate & $191.7 \mathrm{~kg} / \mathrm{s}$ & $191.7 \mathrm{~kg} / \mathrm{s}$ & $191.7 \mathrm{~kg} / \mathrm{s}$ \\
\hline Efficiency (based on LHV) & $23.70 \%$ & $31.59 \%$ & $31.61 \%$ \\
\hline \multicolumn{4}{|c|}{ Independent and Key Dependent Varaibles } \\
\hline $\mathrm{P}_{\mathrm{Comb}}$ & 7.41bar & 7.41bar & 7.41bar \\
\hline$\dot{Q}_{\mathrm{Comb}}$ & $0.6 \mathrm{MW}$ & $0.6 \mathrm{MW}$ & $0.6 \mathrm{MW}$ \\
\hline$\dot{m}_{\mathrm{FW}}$ Main & $179.0 \mathrm{~kg} / \mathrm{s}$ & $167.6 \mathrm{~kg} / \mathrm{s}$ & $169.3 \mathrm{~kg} / \mathrm{s}$ \\
\hline $\mathrm{P}_{\mathrm{BLD} 1}$ & 64.14bar & $60.40 \mathrm{bar}$ & 64.56bar \\
\hline equivalent $\mathrm{P}_{\mathrm{BLD} 1}$ at nominal & 99.00bar & $99.00 \mathrm{bar}$ & 105.0bar \\
\hline$\dot{m}_{\mathrm{BLD} 1}$ & $62.22 \mathrm{~kg} / \mathrm{s}$ & $27.88 \mathrm{~kg} / \mathrm{s}$ & $29.29 \mathrm{~kg} / \mathrm{s}$ \\
\hline $\mathrm{P}_{\mathrm{BLD} 2}$ & 16.31bar & $17.02 \mathrm{bar}$ & 18.78bar \\
\hline equivalent $\mathrm{P}_{\mathrm{BLD} 2}$ at nominal & 26.01bar & 26.01bar & 28.00bar \\
\hline$\dot{m}_{\mathrm{BLD} 2}$ & $14.69 \mathrm{~kg} / \mathrm{s}$ & $7.27 \mathrm{~kg} / \mathrm{s}$ & $8.60 \mathrm{~kg} / \mathrm{s}$ \\
\hline $\mathrm{P}_{\mathrm{BLD} 3}$ & 8.17bar & 10.96bar & 11.19bar \\
\hline equivalent $\mathrm{P}_{\mathrm{BLD} 3}$ at nominal & 16.78bar & 16.78bar & 17.00bar \\
\hline$\dot{m}_{\mathrm{BLD} 3}$ & $9.27 \mathrm{~kg} / \mathrm{s}$ & $4.33 \mathrm{~kg} / \mathrm{s}$ & $4.10 \mathrm{~kg} / \mathrm{s}$ \\
\hline $\mathrm{P}_{\text {Deaerator }}$ & 8.16bar & 10.30bar & 10.61bar \\
\hline$\dot{Q}_{\mathrm{FWH} 1}$ & 87.03MW & $67.21 \mathrm{MW}$ & $67.86 \mathrm{MW}$ \\
\hline$\dot{Q}_{\mathrm{FWH} 2}$ & $27.36 \mathrm{MW}$ & $19.04 \mathrm{MW}$ & 22.72MW \\
\hline $\mathrm{T}_{\text {FG-RHE-out }}$ & $93.8^{\circ} \mathrm{C}$ & $36.9^{\circ} \mathrm{C}$ & $36.9^{\circ} \mathrm{C}$ \\
\hline$\dot{Q}_{\mathrm{RHE}}$ & $58.16 \mathrm{MW}$ & $70.07 \mathrm{MW}$ & 70.07MW \\
\hline \multicolumn{4}{|c|}{ Dependent Variables } \\
\hline $\mathrm{T}_{\text {Cool-Gas }}$ & $2311.3^{\circ} \mathrm{C}$ & $296.4^{\circ} \mathrm{C}$ & $301.3^{\circ} \mathrm{C}$ \\
\hline $\mathrm{T}_{\mathrm{FW}-\mathrm{HRSG} \text {-in }}$ & $305.8^{\circ} \mathrm{C}$ & $290.8^{\circ} \mathrm{C}$ & $295.8^{\circ} \mathrm{C}$ \\
\hline $\mathrm{T}_{\text {Comb-Gas-in }}$ & $296.2^{\circ} \mathrm{C}$ & $283.3^{\circ} \mathrm{C}$ & $287.6^{\circ} \mathrm{C}$ \\
\hline Flue gas fkiwrate in HRSG & $665.0 \mathrm{~kg} / \mathrm{s}$ & $648.4 \mathrm{~kg} / \mathrm{s}$ & $636.8 \mathrm{~kg} / \mathrm{s}$ \\
\hline Condensed water RHE & $17.1 \mathrm{~kg} / \mathrm{s}$ & $19.9 \mathrm{~kg} / \mathrm{s}$ & $19.9 \mathrm{~kg} / \mathrm{s}$ \\
\hline$\Delta P_{H R S G}$ & $0.334 \mathrm{bar}$ & $0.334 \mathrm{bar}$ & $0.334 \mathrm{bar}$ \\
\hline$\Delta P_{\text {pipe }}$ Primary & $0.035 \mathrm{bar}$ & 0.034bar & $0.03 \mathrm{bar}$ \\
\hline$\Delta P_{\text {pipe }}$ secondary & $0.009 \mathrm{bar}$ & $0.008 \mathrm{bar}$ & $0.008 \mathrm{bar}$ \\
\hline$\dot{m}_{\text {FG-Rec-pri }}$ & $166.9 \mathrm{~kg} / \mathrm{s}$ & $165.2 \mathrm{~kg} / \mathrm{s}$ & $165.7 \mathrm{~kg} / \mathrm{s}$ \\
\hline$\dot{m}_{\text {FG-Rec-sec }}$ & $425.9 \mathrm{~kg} / \mathrm{s}$ & $411.0 \mathrm{~kg} / \mathrm{s}$ & $415.8 \mathrm{~kg} / \mathrm{s}$ \\
\hline Rankine cycle net power & 196MW & 242MW & 239MW \\
\hline $\mathrm{T}_{\mathrm{FW} \text {-Recov-out }}$ & $173.3^{\circ} \mathrm{C}$ & $157.2^{\circ} \mathrm{C}$ & $158.4^{\circ} \mathrm{C}$ \\
\hline$P_{\text {HPT }}$ & 160.6bar & 151.0bar & 152.3bar \\
\hline$P_{\text {Reheat }}$ & 42.6bar & 39.66bar & 40.0bar \\
\hline
\end{tabular}


Table 8: $30 \%$ thermal load flexibility

\begin{tabular}{|c|c|c|c|}
\hline Variable & $\begin{array}{l}30 \% \text { thermal load sim- } \\
\text { ulation }\end{array}$ & $\begin{array}{l}30 \% \text { thermal load op- } \\
\text { timization of operation } \\
\text { with nominal load de- } \\
\text { sign }\end{array}$ & $\begin{array}{l}30 \% \text { thermal load opti- } \\
\text { mization of design and } \\
\text { operation }\end{array}$ \\
\hline \multicolumn{4}{|c|}{ Input Parameters } \\
\hline Fuel Flowrate & $9 \mathrm{~kg} / \mathrm{s}$ & $9 \mathrm{~kg} / \mathrm{s}$ & $9 \mathrm{~kg} / \mathrm{s}$ \\
\hline Slurry water flowrate & $4.95 \mathrm{~kg} / \mathrm{s}$ & $4.95 \mathrm{~kg} / \mathrm{s}$ & $4.95 \mathrm{~kg} / \mathrm{s}$ \\
\hline Atomizer Stream flowrate & $0.75 \mathrm{~kg} / \mathrm{s}$ & $0.75 \mathrm{~kg} / \mathrm{s}$ & $0.75 \mathrm{~kg} / \mathrm{s}$ \\
\hline Air flowrate & $102 \mathrm{~kg} / \mathrm{s}$ & $102 \mathrm{~kg} / \mathrm{s}$ & $102 \mathrm{~kg} / \mathrm{s}$ \\
\hline Efficiency (based on LHV) & Infeasible & $24.48 \%$ & $24.48 \%$ \\
\hline \multicolumn{4}{|c|}{ Independent and Key Dependent Varaibles } \\
\hline $\mathrm{P}_{\mathrm{Comb}}$ & 7.41bar & $7.41 \mathrm{bar}$ & $7.41 \mathrm{bar}$ \\
\hline$\dot{Q}_{\mathrm{Comb}}$ & $0.3 \mathrm{MW}$ & $0.3 \mathrm{MW}$ & $0.3 \mathrm{MW}$ \\
\hline$\dot{m}_{\mathrm{FW}}$ Main & & $74.47 \mathrm{~kg} / \mathrm{s}$ & $74.46 \mathrm{~kg} / \mathrm{s}$ \\
\hline$P_{\text {BLD1 }}$ & & & 31.81bar \\
\hline equivalent $\mathrm{P}_{\mathrm{BLD} 1}$ at nominal & 99.00bar & 99.00bar & 106.3bar \\
\hline$\dot{m}_{\mathrm{BLD} 1}$ & & $9.41 \mathrm{~kg} / \mathrm{s}$ & $8.75 \mathrm{~kg} / \mathrm{s}$ \\
\hline $\mathrm{P}_{\mathrm{BLD} 2}$ & & 8.66bar & 10.27bar \\
\hline equivalent $\mathrm{P}_{\mathrm{BLD} 2}$ at nominal & 26.01bar & 26.01bar & 29.90bar \\
\hline$\dot{m}_{\mathrm{BLD} 2}$ & & $3.23 \mathrm{~kg} / \mathrm{s}$ & $4.19 \mathrm{~kg} / \mathrm{s}$ \\
\hline $\mathrm{P}_{\mathrm{BLD} 3}$ & & NA & NA \\
\hline equivalent $\mathrm{P}_{\mathrm{BLD} 3}$ at nominal & 16.78bar & 16.78bar & NA \\
\hline$\dot{m}_{\mathrm{BLD} 3}$ & & $0 \mathrm{~kg} / \mathrm{s}$ & $0 \mathrm{~kg} / \mathrm{s}$ \\
\hline $\mathrm{P}_{\text {Deaerator }}$ & & $5.04 \mathrm{bar}$ & $5.23 \mathrm{bar}$ \\
\hline$\dot{Q}_{\text {FWH1 }}$ & & 24.59MW & $22.67 \mathrm{MW}$ \\
\hline$\dot{Q}_{\mathrm{FWH} 2}$ & & $8.93 \mathrm{MW}$ & 11.78MW \\
\hline $\mathrm{T}_{\text {FG-RHE-out }}$ & & $36.9^{\circ} \mathrm{C}$ & $36.9^{\circ} \mathrm{C}$ \\
\hline$\dot{Q}_{\mathrm{RHE}}$ & & 33.09MW & $33.25 \mathrm{MW}$ \\
\hline \multicolumn{4}{|c|}{ Dependent Variables } \\
\hline $\mathrm{T}_{\text {Cool-Gas }}$ & & $252.6^{\circ} \mathrm{C}$ & $256.0^{\circ} \mathrm{C}$ \\
\hline $\mathrm{T}_{\mathrm{FW}-\mathrm{HRSG} \text {-in }}$ & & $246.9^{\circ} \mathrm{C}$ & $250.3^{\circ} \mathrm{C}$ \\
\hline $\mathrm{T}_{\text {Comb-Gas-in }}$ & & $245.5^{\circ} \mathrm{C}$ & $248.4^{\circ} \mathrm{C}$ \\
\hline Flue gas fkiwrate in HRSG & & $302.4 \mathrm{~kg} / \mathrm{s}$ & $304.0 \mathrm{~kg} / \mathrm{s}$ \\
\hline Condensed water RHE & & $9.96 \mathrm{~kg} / \mathrm{s}$ & $9.96 \mathrm{~kg} / \mathrm{s}$ \\
\hline$\Delta P_{H R S G}$ & & $0.334 \mathrm{bar}$ & $0.334 \mathrm{bar}$ \\
\hline$\Delta P_{\text {pipe }}$ Primary & & 0.008bar & $0.008 \mathrm{bar}$ \\
\hline$\Delta P_{\text {pipe }}$ secondary & & $0.002 \mathrm{bar}$ & $0.002 \mathrm{bar}$ \\
\hline$\dot{m}_{\text {FG-Rec-pri }}$ & & $80.2 \mathrm{~kg} / \mathrm{s}$ & $80.3 \mathrm{~kg} / \mathrm{s}$ \\
\hline$\dot{m}_{\text {FG-Rec-sec }}$ & & $186.2 \mathrm{~kg} / \mathrm{s}$ & $187.5 \mathrm{~kg} / \mathrm{s}$ \\
\hline Rankine cycle net power & & $110 \mathrm{MW}$ & 109MW \\
\hline $\mathrm{T}_{\text {FW-Recov-out }}$ & & $157.2^{\circ} \mathrm{C}$ & $149.8^{\circ} \mathrm{C}$ \\
\hline$P_{\mathrm{HPT}}$ & & 72.1bar & 72.4bar \\
\hline$P_{\text {Reheat }}$ & & 19.8bar & 19.9bar \\
\hline
\end{tabular}


Figure 2: Simulation and optimization of the operation for the full load optimal design at different partloads, in dashed and solid lines respectively. Optimization of the operation of the full load design matches the performance of the optimal design of the specific part load, in (x)'s. The full load design is ideally flexible but optimization is required, while simulation of the full load operation suffers significantly and is even infeasible at relatively small loads. In all designs, the design of the turbine expansion line is fixed to allow for the complete range of load operations.

\subsection{Flexibility Assessment}

The results of the flexibility assessment, Tables $7 \& 8$, show that the process designed for full load is ideally flexible to large load changes. By optimizing the operation of a design specific for the full load while under a partial thermal load (columns 3 in Tables $7 \& 8$ ), the process performance matches the maximum possible performance obtained when the process is designed specifically for that load -apart from the turbines- (columns 4 in Tables $7 \& 8$ ). The discrepancy is approximately $0.02 \%$ and as such insignificant. In contrast, maintaining the nominal load operating conditions when at a partload operation (simulations in columns 2 in Tables $7 \& 8$ ), results in a drastic decrease in the efficiency of the process, around 8 percentage points decrease at the $60 \%$ TLoad, and 30 percentage points $30 \%$ load. Figure 2 represents the results of all the operation ranges graphically, where the optimum operation of the full load design at a particular load matches the respective optimal design of that load, while without optimization the performance suffers significantly and may even be infeasible. Note that the $90 \%$ load has an efficiency of $34.55 \%$, larger than the full load efficiency because the benefits of smaller pressure losses and smaller flue gas flows outweigh the disadvantages of the turbines expansion and turbines bleeds reduction in performance; this validates that the full load design takes economic consideration into account for the sizing of the HRSG and recycling pipes [21].

\subsection{Behavior of Key Variables}

Analyzing the behavior of the variables is crucial to understand the reasons behind the flexibility of the process with respect to loading, in particular the variables related to regeneration and the recovery sections. The behavior of key variables is discussed in this subsection. In the following subsection, Rankine cycles without pressurized thermal recovery and CCS are discussed to argue that they do not exhibit ideal flexibility.

Combustor Pressure, $P_{\text {Comb, operation }} \mathcal{E} P_{\text {Comb, design }}$.

As mentioned above, the operating pressure at optimum is equal to the upper bound of its range, which is the pressure of the design load. Moreover, the design pressure does not change from the nominal design pressure value because the same tradeoff between thermal recovery and pressure losses that exists at full load, [21], also occurs here; although higher operating pressures result in more recovery, it results in larger pressure losses. Also, lower operating pressures reduces the pressure losses, but achieves smaller thermal recovery at the HRSG. First, the thermo-economical optimum design occurs at the same range as that of the nominal design. The pressure is sufficient to allow for the condensation of the majority of the water in the flue gas, by allowing the minimum 
temperature approach to occur at the outlet of the flue gas; note that the pinch also occurs at the onset of water condensation of the flue gas because a lower pressure eliminates the outlet pinch and a higher pressure results in larger pressure drop of the designed HRSG and recycling pipes with no change in the outlet pinch.

Combustor Duty, $\dot{Q}_{\text {Comb }}$.

$\dot{Q}_{\text {Comb }}$ is favored to be the minimum allowed value as it reduces the irreversibilities associated with the heat transfer across a large temperature gradient.

\section{Feedwater Flworate, $\dot{m}_{F W}$ Main.}

As expected, the optimal $\dot{m}_{\text {FW Main }}$ decreases with decreasing thermal load. The amount of thermal energy available for transfer from the HRSG to heat the working fluid upto the nominal working fluid temperatures, $600^{\circ} \mathrm{C}$ for the main stream, and $610^{\circ} \mathrm{C}$ for the reheat stream, results in a smaller working fluid flowrate compared to the full load operation. At any fixed thermal load, a larger main feedwater flowrate in general signifies a larger power output and a larger efficiency, columns $3 \& 4$ of Tables $7 \& 8$. However, this is not the case looking at Column 1 of the same tables. The main feedwater flowrate is large but the working fluid flowrate decreases significantly through the expansion line due to the suboptimal high bleeds flowrates, resulting in a significant decrease of efficiency. Notice that the pressure at the inlet to the high-pressure turbine and the intermediate pressure turbine, $P_{\text {HPT }} \&$ $\mathrm{P}_{\text {Reheat }}$ respectively, decrease with the decrease in working fluid flowrate in order to satisfy the turbines constraints of constant volumetric flowrates. At $60 \%$ and $30 \%$ thermal load, the process is subcritical, i.e., there is a phase change of the feedwater in the HRSG, see Section 5.4. It is important to realize that in the two optimized runs of each load, optimization of operation and optimization of design and operation, the ratio of the working fluid

flowrate, $\frac{\dot{m}_{\mathrm{FW} \text { Main, pload }}}{\dot{m}_{\mathrm{FW} \text { Main, nominal }}}$ is almost equal to the thermal load; this fact is due to the thermal recovery section, and is fundamental in explaining the reasons behind the flexibility. The argument that the recovery section is responsible for the working fluid ratio relative to nominal being proportional to the thermal load is proven in Section 5.3, but considered as an observation/result in what follows.

Recovery Section (condensed water, $\left.\dot{Q}_{R H E}, T_{F G-R H E-o u t}, T_{F W-R H E-o u t}\right)$.

Before discussing the behavior of the regeneration bleeds, it is important to understand the thermal recovery section (after the condenser, before the deaerator), which the working fluid passes through prior to regeneration. The overall flue gas flowrate scales according to the thermal load and has almost identical composition with the flue gas at nominal conditions; the fuel flowrate, the oxygen flowrate, and the added water flowrate scale from their nominal values according to the operation thermal load. Similarly, the overall thermal energy available for transfer also scales proportionally with the thermal load. Now, due to the invariant flue gas composition in particular water fraction, the ratio of the low-grade thermal energy, transferred at the RHE/recovery, to the total thermal energy transferred into the Rankine cycle is almost constant (and equal to the same ratio at nominal load); note that in the pressurized OCC process the temperature of the flue gas exiting the HRSG/entering the RHE, $\mathrm{T}_{\mathrm{Cool}-\mathrm{Gas}}$, is almost 
equal in the optimum operations at different loads. As a result, the amount of recovered thermal energy, at any load, relative to the nominal load is proportional to the thermal load; in summary, $\frac{\dot{Q}_{\text {Total,Tload }}}{\dot{Q}_{\text {Total, } 100 \%}}=$ Tload $\& \frac{\dot{Q}_{\text {RHE }}}{\dot{Q}_{\text {Total }}}=$ constant $\Rightarrow \frac{\dot{Q}_{\text {RHE,Tload }}}{\dot{Q}_{\text {RHE, 100\% }}}=$ Tload. This is validated by comparing the results of $\dot{Q}_{\text {RHE }}$ in the optimized runs, or comparing the amount of water condensed from the flue gas in the RHE $(33.2 \mathrm{~kg} / \mathrm{s}, 19.9 \mathrm{~kg} / \mathrm{s} \mathrm{\&} 9.96 \mathrm{~kg} / \mathrm{s}$ at $100 \%$, $60 \% \& 30 \%$ thermal loads respectively).

Recall that the working fluid mass flowrate in the optimized partload operations and optimized partload designs above scales with the thermal load and that the condenser temperature is constant at any load. Therefore, the extensive properties of the thermal recovery section at the optimized partloads is almost identical to the recovery section at nominal load, which is verified by the results; namely the temperature of the flue gas exiting the RHE, $\mathrm{T}_{\mathrm{FG}-\mathrm{RHE}-\text { out }}$, and the temperature of the feedwater exiting the RHE, $\mathrm{T}_{\mathrm{FW}-\text { Recov-out }}$. Therefore, a unit mass of the working fluid leaving the condenser and before reaching the deaerator always experiences identical conditions irrespective of the load, the turbine expansion line pressure ranges, or the regeneration bleeds extraction pressures and flowrates. The nominal load recovery is suited for a power plant with supercritical pressures and large pressure ranges equal to those of the basecase nominal load operation; yet, at partload the recovery is operating within smaller pressure ranges. In other words, the scaled version of the thermal recovery section is more than adequate in heating the working fluid during partload and takes over relatively larger and larger fractions of the working fluid's gradual preheating processes with decreasing load; thus compensates for the regeneration process which inherently and independently faces diminishing performance as explained next. In conclusion, the thermal recovery in a pressurized OCC process results in two advantages: first, the maximum efficiency of partload is only slightly lower than the maximum efficiency of the nominal load, and second, the process designed for nominal load can attain a performance that matches the maximum possible performance at any load.

Another way to explain the importance of the recovery section is by realizing that at nominal loading the recovery, with the help of the dearator bleed, is able to sustain a deaerator pressure of around 14bar, and thus bleed 3 is extracted from the turbine expansion line withing the same range of pressure. At partload, the recovery is unaffected, and able to deliver the working fluid with similar conditions as those of nominal, i.e., sustaining the high deaerator pressure; however, at partload, the same value of pressure for the dearator bleed resembles earlier extraction positions, signifying that the recovery section is contributing to a larger fraction of the working fluid preheating, and is taking over the regeneration which faces diminishing effectiveness with decreasing load.

Recall that initially the recovery section replaces a number of low-pressure feedwater heaters and regeneration bleeds found in standard Rankine cycles without pressurized recovery. Unlike the recovery section, the regeneration section is highly affected by the turbines' pressure ranges and bleeds' extraction pressures. Therefore, a standard Rankine cycle without a pressurized recovery section is expected to be inflexible to variable loading, and has a partload performance, whether optimized operation or optimized design, significantly lower than that of the nominal, as elaborated in Section 5.3. 
Regeneration Section, Bleeds pressures and flowrates.

With the decrease in the expansion line inlet pressures and pressure ranges, the pressure of a bleed withdrawn from the fixed extraction position decreases, and so does its saturation temperature. The decrease of the bleed's saturation temperature limits the temperature rise of the feedwater in the feedwater heater decreasing the quantity and quality of regeneration. Therefore, with decreasing thermal load and decreasing expansion line pressure ranges, a unit mass of regenerative bleed extracted from a fixed position is relatively less beneficial to the unaltered temperature of the feedwater entering the regeneration section; in the pressurized OCC considered herein the regeneration section starts with the deaerator while in non-pressurized OCC processes it starts at the exit of the low-pressure pump after the condenser. The high-temperature source of thermal energy, the flue gas in the HRSG, is still operating at approximately the same temperature ranges; therefore in general, a decrease in the effectiveness of regeneration reduces the temperature of the feedwater entering the HRSG, and causes a decrease in the exergy of the transferred thermal energy at the HRSG, reducing the efficiency of the process. The effect of the decrease in recovery effectiveness on the Rankine cycle performance is alleviated when a pressurized recovery section is present as explained next.

The reduction of the regeneration effectiveness at partload is one of the reasons why in the simultaneous optimization of design and operation of the pressurized OCC the extraction pressures of the bleeds increase compared to those obtained by the nominal extraction positions operating at the same load. This signifies that the extraction positions shift to earlier sections along the expansion line; the smaller the load, the earlier the designed extraction position is. The second reason behind the earlier extraction positions of the bleeds is that the recovery section covers a relatively larger preheating portion and therefore higher quality regeneration is required; (as if additional feedwater heaters are introduced before FWH1\&2, thus FWH1\&2 move upwards in pressure). For example, for bleed1, the nominal extraction position of $99.00 \mathrm{bar}$ at nominal load results in a $60.40 \mathrm{bar}$ at $60 \%$ partload. After redesigning for the $60 \%$ load, the extraction pressure is $64.56 \mathrm{bar}$ equivalent to $105.0 \mathrm{bar}$ at nominal conditions. Similarly for the $30 \%$ load, the optimal design extraction position occurs even earlier with an equivalent pressure of 106.3bar at nominal conditions. However, due to the behavior of the recovery section, which is independent of the thermal load, there is not a big advantage in redesigning the regeneration and extractions for a specific partload. In other words, while the regeneration effectiveness of the bleeds and feedwater heaters decrease with smaller loads, which here necessitates earlier and earlier extraction positions, the effectiveness of the recovery section, relative to the smaller working fluid pressure ranges, increases and takes over the regeneration section. The independence of the thermal recovery section to the turbine expansion line pressure ranges is the main reason behind the flexibility of the process. This behavior is best explained by the response of the deaerator bleed/BLD3, where at partload there is very little interest in a deaerator bleed. In particular, the $30 \%$ load requires no deaerator bleed. This is a definite illustration of how the recovery section takes on a larger role with the decrease in the thermal load till eventually eliminating one bleed altogether. Another reason for flexibility, also in favor of the 
recovery section, is that the recovery section replaces the low-temperature feedwater heaters where the bleeds' saturation temperatures, and thus bleeds' quality, are highly sensitive to the bleeds' pressures and the turbine pressure ranges; while the saturation temperature of the high-pressure bleeds, namely bleeds $1 \& 2$ of FHW1\&2 in the pressurized OCC process, are relatively less sensitive to the pressure ranges. Note that if the conditions of the feedwater entering the FWHs are altered significantly, like what would be the case if low-pressure feedwater heaters are present instead of the recovery section, then the high-pressure feedwater heaters and bleeds require significant change in design and result in a significantly different performance.

The behavior of the bleeds' flowrates are justified for similar reasons. As the load decreases the bleeds' flowrates decrease; first, the working fluid has a lower flowrate and thus requires smaller regeneration. Second, the recovery section takes a larger portion of the working fluid preheating and less regeneration is required. Finally, with the decrease in saturation temperature of the bleeds, due to the decrease in the pressure ranges of the turbines, the possible temperature rise of the working fluid is smaller and thus smaller bleeds flowrates are required.

\subsection{Standard Rankine Cycles Without Pressurized Recovery}

In Section 5.2 it was argued that in the OCC process considered, the thermal recovery section allows ideal flexibility with respect to thermal load. A key to achieve this was that the mass flowrate of the working fluid is proportional to the load. Herein, it is argued that this proportionality is enabled by the thermal recovery section and that Rankine cycles without pressurized recovery section do not show this ideal flexibility.

In Rankine cycles without pressurized recovery, where the boiler is the only site of thermal energy transfer from the flue gas, the amount of thermal energy transferred to the working fluid relative to that at nominal approximately scales with the thermal load; (as seen later, the temperature of the flue gas at the outlet of the boiler in a partload operation is generally smaller than that at nominal and thus the proportionality is not exact). However, unlike the pressurized OCC process, the working fluid flowrate does not scale linearly with the thermal load because the quality of the transferred thermal energy decreases compared to the nominal operation. The argument is illustrated by contraposition; assume in a Rankine cycle without pressurized recovery that the flowrate of the working fluid scales with the thermal load. The decrease in the fluid mass flowrate at partload from its nominal value results in lower pressure ranges of the turbine due to the requirement of constant volumetric flowrate. The regeneration section, which is the only section responsible for the gradual preheating of the working fluid, decreases in effectiveness relative to the nominal conditions due to the decrease in the expansion line and bleeds' pressures (even if regeneration is redesigned for that specific load). As a result, the temperature of the working fluid entering the boiler is lower than that of the nominal operation. Therefore, part of the thermal energy transfer at the boiler is required to compensate for the deficiency in the working fluid's temperature, and therefore by conservation of energy, the mass flowrate of the working fluid has to be smaller than that originally assumed. The even smaller flowrate results in even smaller pressure ranges of the turbines, smaller regeneration effectiveness, and smaller temperature of the working fluid entering the boiler, etc. As mentioned above, this behavior can be 
considered as a decrease in the quality of the transferred thermal energy because the average temperature of the feedwater in the boiler is smaller due to the lower temperature of the feedwater entering the boiler/exiting the less effective regeneration. To be more rigorous, note that since the temperature of the working fluid entering the boiler decreases, the temperature of the flue gas exiting the boiler can decrease too. However, the increased amount of thermal energy transfer due to the larger flue gas temperature drop is smaller than the amount of thermal energy required to elevate the smaller temperature of the working fluid entering the boiler because the thermal capacity of the flue gas is smaller than that of the working fluid, guaranteeing that the mass flowrate of the working fluid relative to the nominal scales sublinearly with the thermal load. The fact that the thermal capacity of the flue gas is smaller than that of the working fluid can be deduced in several ways, $\mathrm{i}$ - the pinch inside the HRSG occurs at the cold end of the exchanger (flue gas exit, feedwater inlet), ii- the temperature drop of the flue gas is much larger than the temperature increase of the feedwater and the reheat streams, iii- regeneration increases efficiency, ivand of course can be seen by comparing the temperature profiles of the streams in the HRSG where the hot stream profile is steeper than that of the cold stream, etc.

Coal-fired Rankine cycles without pressurized recovery have another limitation for partload operation. At some thermal load the temperature of the working fluid entering the boiler will fall below the acid condensation temperature, thus further limiting the heat transfer from the flue gas. This further deteriorates the performance of the Rankine cycle subject to variable loading.

Moreover, Rankine cycles without pressurized recovery have larger number of FWHs, particularly low-pressure FWHs, compared to the pressurized OCC process of the same size. The sensitivity of the larger regeneration section to the turbine pressure ranges, especially at the low-pressures, results in a large difference between the designs of the non-pressurized recovery process at different loads. Thus, rendering the process inflexible and further deteriorating the performance when a fixed design is operated under variable loading.

In contrast, due to the recovery section in the pressurized OCC process, which increases in effectiveness and takes over the regeneration section with decreasing load, the temperature of the working fluid entering the HRSG barely changes, resulting in the aforementioned linear relation of the working fluid to the thermal load. Nevertheless, the process remains unconstrained by the acid condensation temperature constraints, and therefore operates at the unconstrained optimum and maintains a high performance. For further elaboration, using the same argument used for processes without pressurized recovery, it can be shown that the optimal ratio of the flowrate in the pressurized OCC process is actually sustainable, and the results seen in the optimized runs in the above tables are not coincidental. The increased effectiveness of the recovery section compensates for the decrease in the effectiveness of the recovery section, thus maintaining the temperature of the feedwater entering the HRSG close to nominal and allows for the scaled ratio of the working fluid. 
5.4. Partload and Subcritical Operation

As the load and the mass flowrate of the working fluid decrease, the turbine inlet pressures and pressure ranges decrease to satisfy the turbine expansion line constraints of constant volumetric flowrate profile. At some flowrate the required working fluid pressure falls below critical and the process becomes subcritical, where there is a phase change of the feedwater in the HRSG, and through out that phase change a constant saturation temperature is maintained. The lower the feedwater pressure, the lower the saturation temperature, and the larger the enthalpy of vaporization. A larger enthalpy of vaporization signifies that more thermal energy is transferred to the relatively low-temperature of saturation, decreasing the exergy of the transferred thermal energy. Moreover, the presence of a larger range where the temperature of the feedwater is constant results in decreasing the temperature difference at the cold end of the HRSG and in reaching the minimum allowed temperature difference, which limits the flow of the feedwater. The efficiency of the $30 \%$ load is relatively small compared to the efficiencies of the $60 \%$ load, relatively high saturation temperature, and to the $100 \%$ loads, supercritical, which are not that different from each other. Note that in non-pressurized recovery Rankine processes, the subcritical conditions are reached earlier/at larger partloads, and the saturation temperatures for a given subcritical load are lower, than those of the pressurized OCC process; this is due to the fact that the flowrate of the feedwater decreases at a faster rate in conventional Rankine cycles compared to the pressurized OCC process.

\section{Conclusion}

The flexibility of the ENEL/ITEA pressurized OCC process to variable load is evaluated with an accurate representation of unit operations particularly the turbine expansion line. The turbines operate at constant volumetric fluid flowrate profile which requires changing the turbine inlet pressures and pressure ranges with the change in load. The results show that the process is ideally flexible for variable load due to the characteristics of the thermal recovery section. The performance of the nominal load design when operating at a given partload matches the maximum performance of the process designed specifically for that partload. When designing the process specific to a partload, the turbines are maintained at the nominal load design in order to allow for a full range of load operations. The ideally flexible behavior is owed to the thermal recovery section, which is not affected by the reduction of the pressure ranges of the turbine expansion line with decreasing thermal load. The recovery section always provides adequate preheating to the working fluid. In particular, a unit flowrate of working fluid always receives the same preheating from the flue gas at the thermal recovery section independent of the operating load. This signifies a relatively larger preheating duty with the decrease in the turbine pressure ranges; the recovery section compensates the decrease in the effectiveness of the inflexible regeneration section, and therefore, the OCC process is ideally flexible. This flexibility is in contrast to Rankine cycles without pressurized recovery, wherein the performance significantly deteriorates compared to the nominal operation. Moreover, as the thermal load and the working fluid flowrate decrease, the required turbine pressures fall below the critical pressure, and the working 
$\overline{\text { fluid in the HRSG pass through the saturation region. However, this transition occurs at a larger load for Rankine }}$ processes without pressurized recovery compared to the pressurized OCC processes which are able to maintain supercritical conditions at smaller thermal loads.

Due to the increasing effectiveness of the recovery section, the working fluid entering the HRSG is high enough such that the flue gas of the pressurized OCC process never violates the acid condensation constraints even at extremely low loads. In contrast, due to the reduction in the effectiveness of regeneration, conventional coal Rankine cycles are constrained by the acid condensation temperatures at certain part loads, and therefore operate sub-optimally with a low performance.

\section{Acknowledgments}

This work is conducted with the financial support from ENEL. This material is based upon work supported by the Department of Energy under Award Number DE-FE0009478. AspenPlus was generously provided by AspenTech. The authors would also like to thank Nicola Rossi and his team at ENEL for their interest and feedback.

\section{Disclaimer}

This report was prepared as an account of work sponsored by an agency of the United States Government. Neither the United States Government nor any agency thereof, nor any of their employees, makes any warranty, express or implied, or assumes any legal liability or responsibility for the accuracy, completeness, or usefulness of any information, apparatus, product, or process disclosed, or represents that its use would not infringe privately owned rights. Reference herein to any specific commercial product, process, or service by trade name, trademark, manufacturer, or otherwise does not necessarily constitute or imply its endorsement, recommendation, or favoring by the United States Government or any agency thereof. The views and opinions of authors expressed herein do not necessarily state or reflect those of the United States Government or any agency thereof.

\section{References}

[1] G. Benelli, M. Malavasi, G. Girardi, Innovative oxy-coal combustion process suitable for future and more efficient zero emission power plants, Proceedings of the Power-Gen Europe (2007) paper ID 194.

[2] G. Benelli, D. Cumbo, M. Gazzino, E. Morgani, Pressurized oxy- coal combustion with flue gas recirculation pilot scale demonstration, Proceedings of the Power-Gen Europe (2008) paper ID 67.

[3] M. Gazzino, G. Benelli, Pressurized oxy-coal combustion Rankine-cycle for future zero emission power plants: Process design and energy analysis, ASME Conference Proceedings (43208) (2008) 269-278.

[4] M. Gazzino, G. Riccio, N. Rossi, G. Benelli, Pressurized oxy-coal combustion rankine-cycle for future zero emission power plants: Technological issues, Proc. Energy Sustainability, eds., ASME, San Francisco, CA, USA.

[5] H. Zebian, A. Mitsos, Pressurized oxycoal combustion: Ideally flexible to uncertainties, Energy, (2013). 
[6] A. Pickard, G. Meinecke, The future role of fossile power generation, Siemens AG: Energy Sector (2011).

[7] P. Denholm, Y.-H. Wan, M. Hummon, M. Mehos, An analysis of concentrating solar power with thermal energy storage in a California $33 \%$ renewable scenario (2013).

[8] D. Mallinson, W. Lewis, The part-load performance of various gas-turbine engine schemes, Proceedings of the Institution of Mechanical Engineers 159 (1) (1948) 198-219.

[9] T. S. Kim, S. T. Ro, The effect of gas turbine coolant modulation on the part load performance of combined cycle plants. part 1: Gas turbines, Proceedings of the Institution of Mechanical Engineers, Part A: Journal of Power and Energy 211 (6) (1997) 443-451.

[10] D. L. Chase, Combined-cycle development evolution and future, (Oct. 2010), Tech. rep., http://site.geenergy.com/prod_serv/products/tech_docs/en/downloads/ger4206.pdf; (accessed April 23, 2013).

[11] T. Kim, S. Hwang, Part load performance analysis of recuperated gas turbines considering engine configuration and operation strategy, Energy 31 (2006) $260-277$.

[12] A. C. McMahan, Design and optimization of organic Rankine cycle solar-thermal power plants, Master's thesis, University of WisconsinMadison (2006).

[13] E. Lizarraga-Garcia and A. Ghobeity and M. Totten and A. Mitsos. Optimal Operation of a Solar-Thermal Power Plant with Energy and Electricity Buy-Back from Grid. Energy 51 (2013): 61-70.

[14] A. Ghobeity and E. Lizarraga-Garcia and A. Mitsos. Optimal Design and Operation of a Volumetric Solar-Thermal Energy Receiver and Storage, ECOS 2011, The 24th International Conference on Efficiency, Cost, Optimization, Simulation and Environmental Impact of Energy Systems, Novi Sad, Serbia, July 4-7, 2011.

[15] A. Ghobeity and A. Mitsos. Optimal Design and Operation of a Solar Energy Receiver and Storage, ASME Journal of Solar Energy Engineering 134 (3) (2012), 031005:1-9

[16] E. J. Sheu and A. Mitsos. Optimization of a Hybrid Solar-Fossil Fuel Plant: Solar Steam Reforming of Methane in a Combined Cycle. Energy 51 (2013) 193-202.

[17] M. Judes, G. Tsatsaronis, Design optimization of power plants by considering multiple partial load operation points, Proceedings of the ASME International Mechanical Engineering Congress and Exposition 2007, Vol 6 - Energy Systems: Analysis, Thermodynamics and Sustainability (2008) 217-225.

[18] G. Weber, W. Worek, Sliding pressure analysis using the second law, Heat Recovery Systems and CHP 13 (3) (1993) 253 - 260.

[19] S. Sengupta, A. Datta, S. Duttagupta, Exergy analysis of a coal-based 210 MW thermal power plant, International Journal of Energy Research 31 (1) (2007) 14-28.

[20] K. Jonshagen, M. Genrup, Improved load control for a steam cycle combined heat and power plant, Energy 35 (4) (2010) 1694 - 1700 , Demand Response Resources: The US and International Experience.

[21] H. Zebian, M. Gazzino, A. Mitsos, Multi-variable optimization of pressurized oxy-coal combustion, Energy 38 (1) (2012) 37 - 57.

[22] H. Zebian, N. Rossi, M. Gazzino, D. Cumbo, A. Mitsos, Optimal design and operation of pressurized oxy-coal combustion with a direct contact separation column, Energy 49 (2013) 268-278.

[23] H. Zebian, A. Mitsos, A double-pinch criterion for regenerative Rankine cycles, Energy 40 (1) (2012) 258 - 270.

[24] H. Zebian, A. Mitsos, A double pinch criterion for optimization of regenerative rankine cycles, U.S. Patent Application Serial No.: 13/475,816 (May 2012).

[25] A. Stodala, Steam and gas turbines, authorized translation by L. C. Loewenstien, 2nd edition. P. Smith 1945, New York.

[26] Turbine and auxiliaries, nuclear training course 234, module 234-01, the steam turbine, OPG (1994). https://canteach.candu.org/Content2013).

[27] B. P. Vitalis, Riley Power Inc., Constant and sliding-pressure options for new supercritical plants, Power Magazine (Feb 15 2006).

[28] H. Termuehlen, W. Emsperger, Pulverized-Coal-Fired Power Plant Performance and Operating Flexibility, 1st Edition, ASME Press, 2003.

[29] G. Benelli, G. Girardi, M. Malavasi, A. Sponaro, Isotherm: A new oxy-combustion process to match the zero emission challenge in 
power generation (2008).

[30] A. F. Mills, Heat Transfer, Prentice Hall. Inc., 1999.

[31] F. M. White, Fluid Mechanics, McGraw-Hill, 2008.

[32] J. Hong, R. Field, M. Gazzino, A. Ghoniem, Operating pressure dependence of the pressurized oxy-fuel combustion power cycle, Energy 35 (2010) 5391-5399.

[33] U. S. Department of Energy, Advanced Manufacturing Office, Deaerator in industrial steam systems, http://www1.eere.energy.gov/manufacturing/tech_assistance/pdfs/steam18_steam_systems.pdf (accessed Sept 2013).

[34] A. Fassbender, Pressurized oxy-fuel combustion for multi-pollutant capture. The 30th international technical conference on coal utilization and fuel systems, Clearwater, FL, USA, 2005.

[35] A. Fassbender, Simplification of carbon capture power plants using pressurized oxyfuel. The 32nd international technical conference on coal utilization and fuel systems, Clearwater, FL, USA, 2007.

[36] R. Henry, Modeling of pressurized oxy-fuel for recovery of latent heat and carbon capture using usibelli coal. The 32nd international technical conference on coal utilization and fuel systems, Clearwater, FL, USA, 2007.

[37] L. Zheng, R. Pomalis, B. Clements, Technical feasibility study of TIPS process and comparison with other CO2 capture power generation processes. The 32nd international technical conference on coal utilization and fuel systems, Clearwater, FL, USA, 2007.

[38] R. Pomalis, L. Zheng, B. Clements, ThermoEnergy integrated power system economics. The 32nd international technical conference on coal utilization and fuel systems, Clearwater, FL, USA, 2007.

[39] A. Fassbender, L. Tao, R. Henry, Physical properties and liquid vapor equilibrium of pressurized CO2 rich gases from pressurized oxy-fuel combustion of coal. The 33rd international technical conference on coal utilization and fuel systems, Clearwater, FL, USA, 2008.

[40] C. Zheng, L. Zheng, R. Pomalis, R. Turner, B. Clements, Conceptual design and experimental study overview: flue gas treatment and $\mathrm{CO} 2$ recovery experimental system for high pressure oxygen fired coal combustion. The 33rd international technical conference on coal utilization and fuel systems, Clearwater, FL, USA, 2008. 
Figures

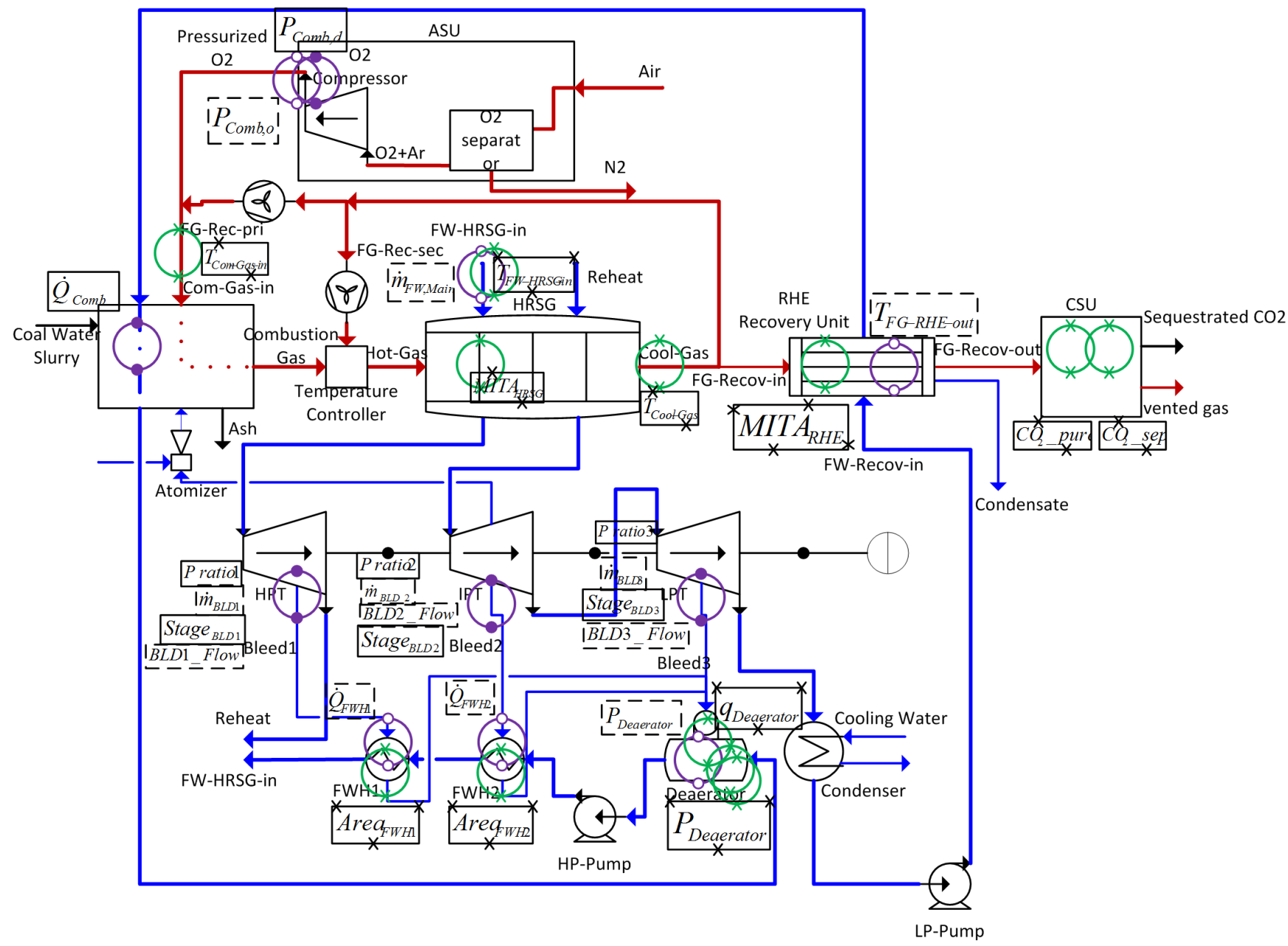

Figure 1: Oxycombustion cycle flowsheet based on wet recycling. Note that this schematic does not represent entirely the modeling, e.g., turbines were modeled with multiple sections in AspenPlus ${ }^{\circledR}$ 


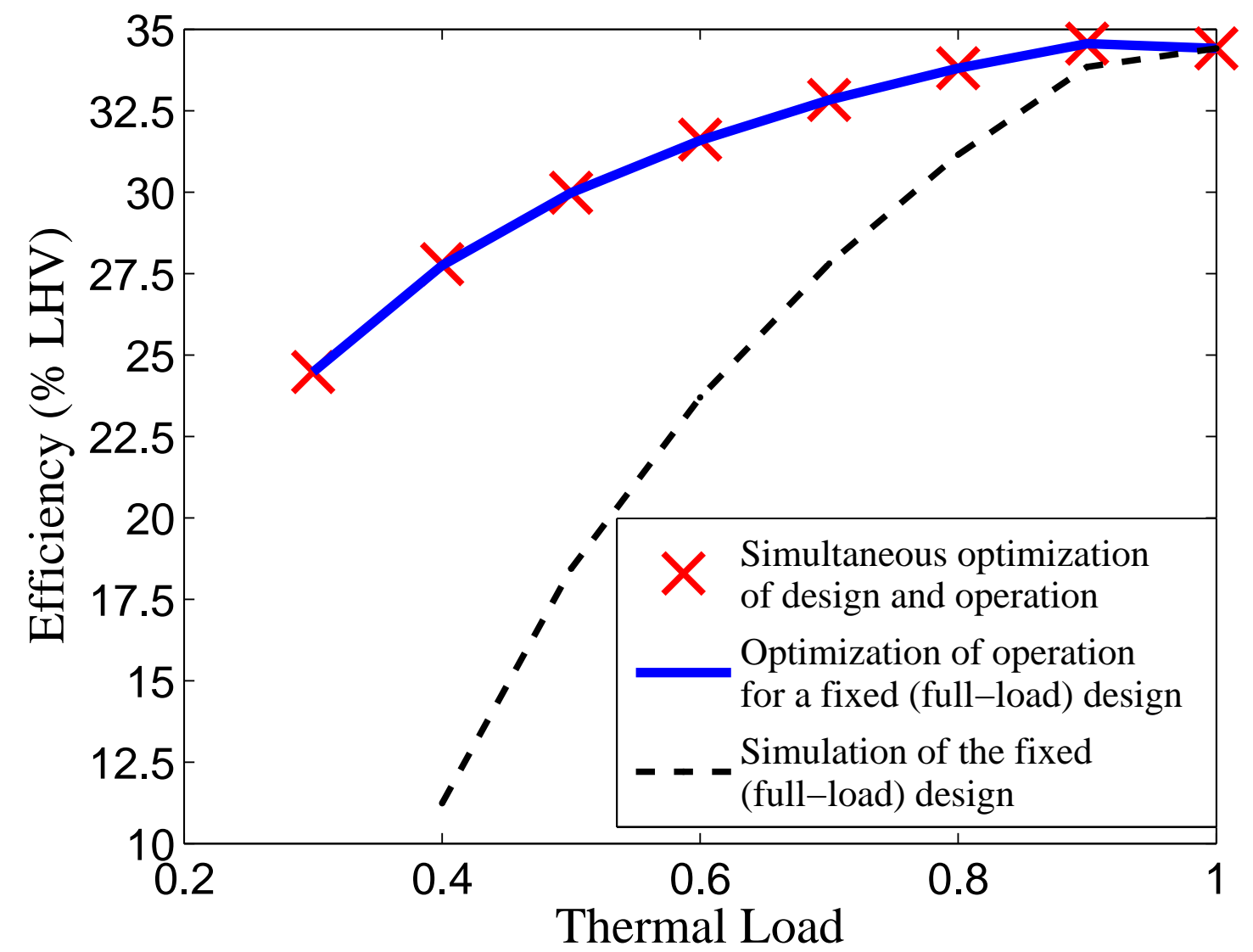

Figure 2: Simulation and optimization of the operation for the full load optimal design at different partloads, in dashed and solid lines respectively. Optimization of the operation of the full load design matches the performance of the optimal design of the specific part load, in (x)'s. The full load design is ideally flexible but optimization is required, while simulation of the full load operation suffers significantly and is even infeasible at relatively small loads. In all designs, the design of the turbine expansion line is fixed to allow for the complete range of load operations. 